اثر التدريب الذهني بالأسلوب المباثر وغير المباثر في مستوى

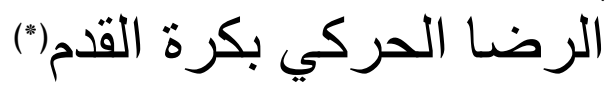

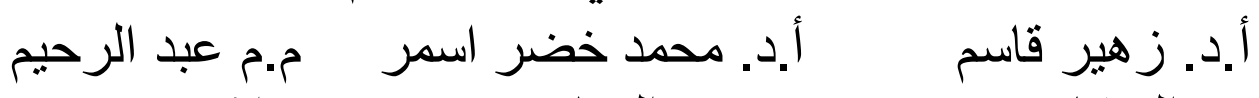

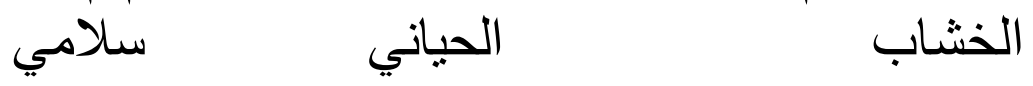

جامعة الموصل / كلية التربية الرياضية

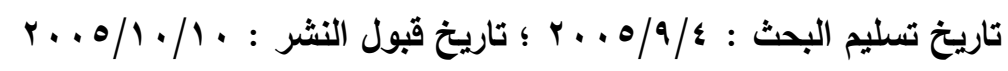

ملخص البحث: : - 20

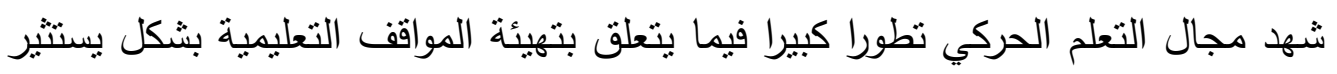

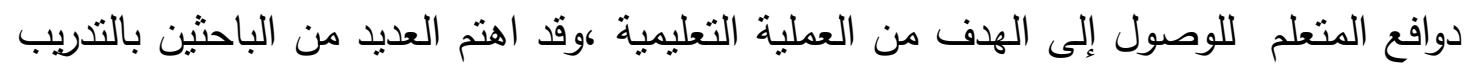

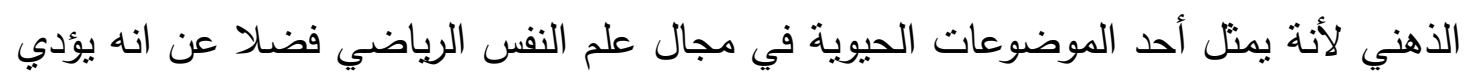

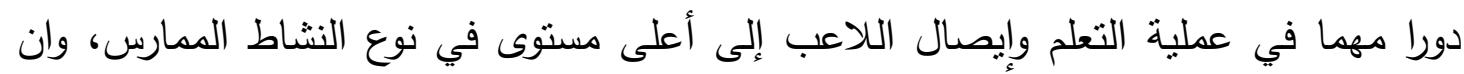
النجاح في أداء النشاط الحركي برتبط بحالة رضا النها المتعلم عن مستوى ادائة . هدف البحث إلى :

1. الكثف عن اثر التدريب الذهني بالأسلوب المباشر وغير المباشر والاعتيادي في مستوى

$$
\text { الرضا الحركي }
$$

r. الكثف عن الفروق بين مجاميع البحث الثناث في الاختبارات البعدية في مستوى الرضا

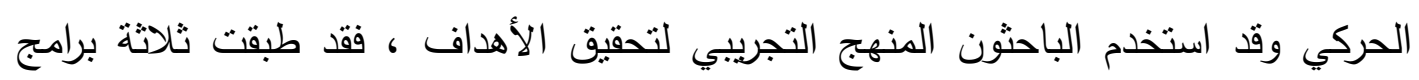

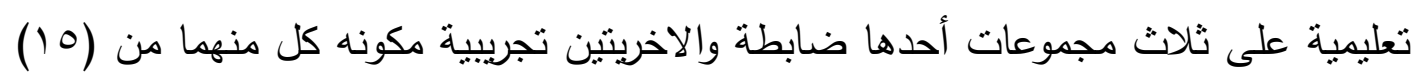

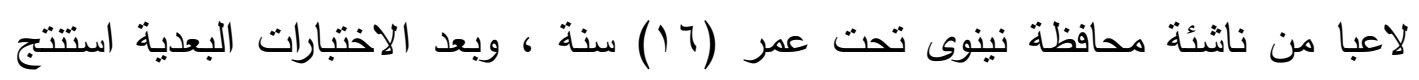

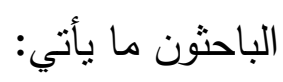

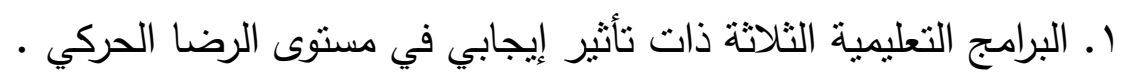

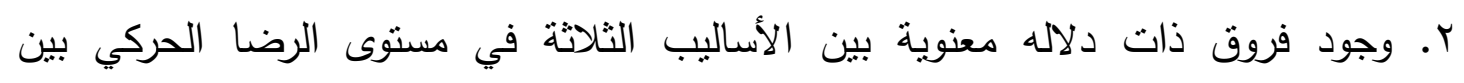

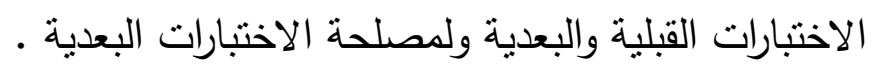

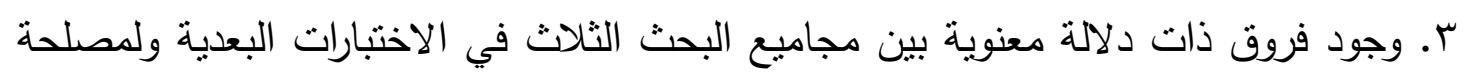

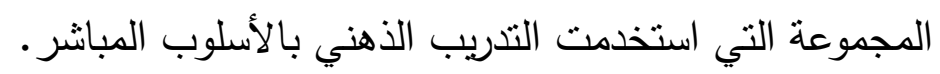
وقد أوصى الباحثون بما يأتي: 1. التأكيد على استخدام التدريب الذهني بأبنائ بأسلوبية المباشر وغير المباشر في العملية التعليمية.

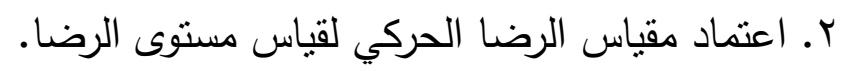

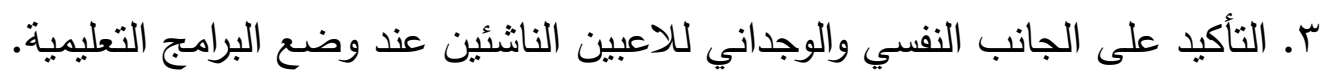




\title{
The effect of direct and indirect mental training on the level of motor Satisfiction in football
}

\author{
Prof. Dr :Zuhair K. Al-khashab \\ Prof. Dr :Mohammed K. Assmar Al-Hayane \\ Assist. Lecturer: Abdul R. Salami \\ University of Mosul - College of Sport Education
}

\section{Abstract:}

The research aims are :

1. Detecting the effect of normal, direct, and indirect methods of mental training on the level of motor satisfiction .

2. Detecting the differncess among the three research groups in the posttests concerning the level of motor satisfiction in football .

- The researchers have used the experimental method to achieve the afore Mentioned objectives, and three learning programes have been applied on three groups, the first is a control one whereas the two are experimintal, each of them is made up of (15) novice players affiliating to the Ninava governorate team under (16) years .

- Having made the post-test, the resarchers concluded the following :

1. The three learning programes have a positive effect on the level of motor satisfiction .

2. There are significant differences among the three methods in the level of motor satisfiction between pre- and post - tests in the penefit of post- tests .

3. There are significant differences among the three methods of research in the group using the direct method of mental training .

Finally, the researchers have recommended that :

1. The emphasis be made on the use of both the direct and indirect methods of mental training within the learning process.

2. The reliance on the motor satisfiction criterion to the measure the level of motor satisfiction. 
3. The emphasis be made on the phychological and emotional aspcts of the novice players on prepearing the learning programes .

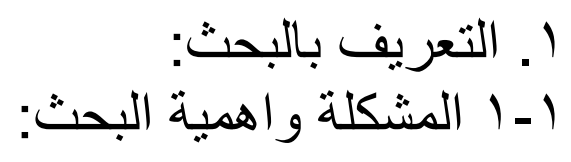

شهد مجال التعلم الحركي تطوراً كبيراً فيما يتعلق بتهيئة المواقف التعليمية بشكل يستشير

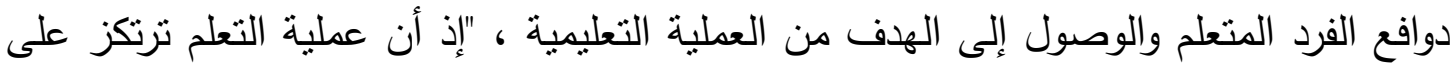
وسيلة مهمة لنقل المعارف والمعلومات من الددرب إلى اللاعب ، وهذه الوسيلة هي طريقة التعلم

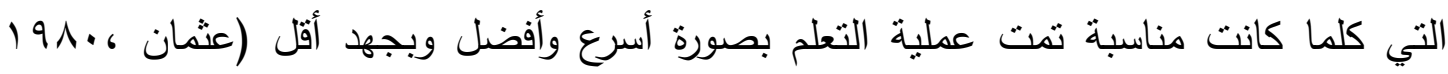

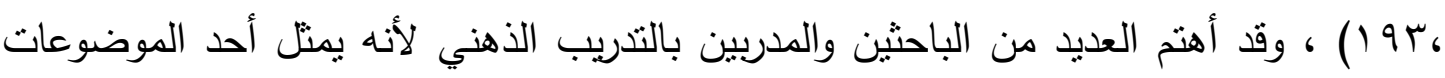

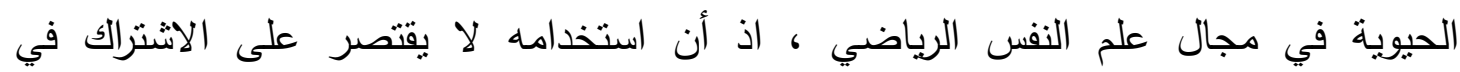
المنافسات فقط بل بستخدم في مجال الحركة بشكل عام وفي مراحل اكتساب المهارات الحركية

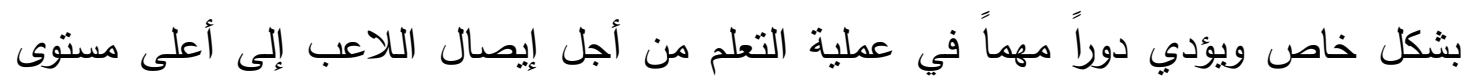

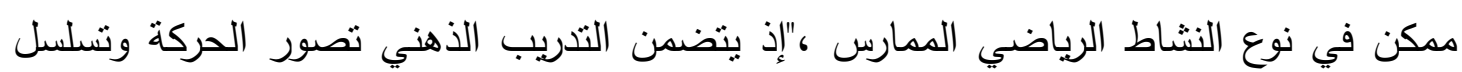

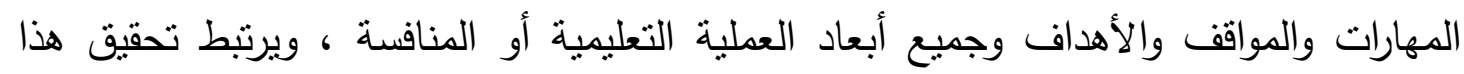

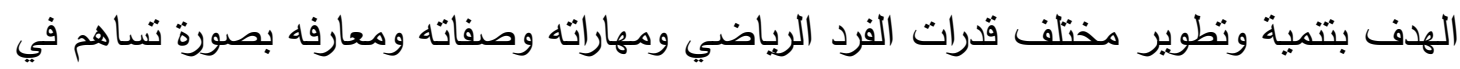

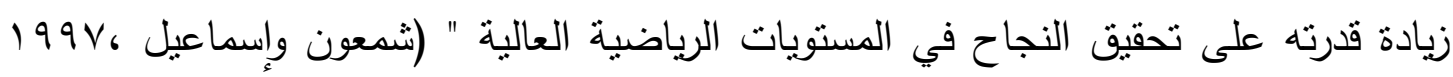

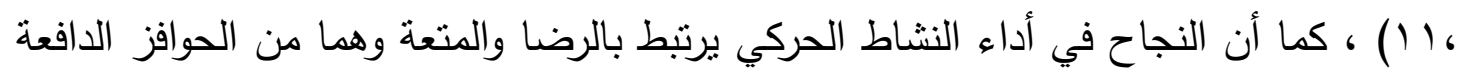

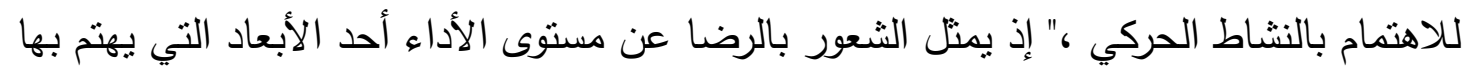

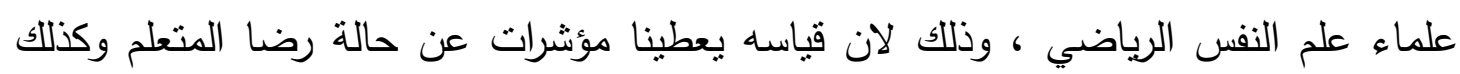

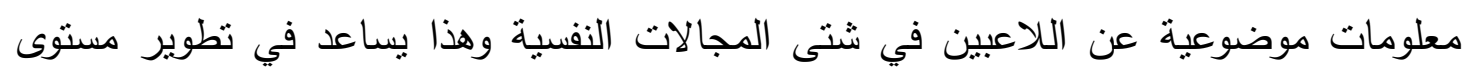

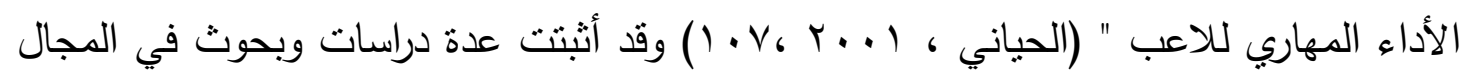

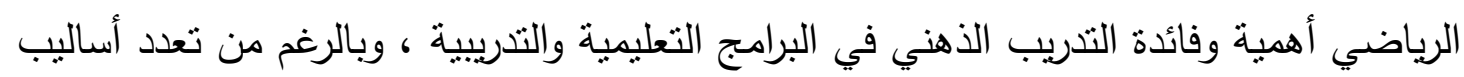
التدريب والذهني وقلة الدراسات والبحوث التي أجريت في مجال التدريب الذهني وخاصة في لعبة التبات كرة القدم لاحظ الباحثون انه تم استخدام التدريب الذهني المباشر فقط ولم يشر إلى الثى الأسلوب

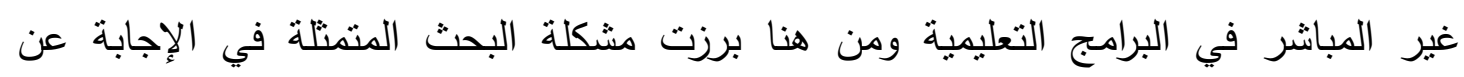
التساؤلات الآتية : التئ

1- هل ان التدريب الذهني بالأسلوب المباشر وغير المباشر المصاحب للتدريب المهاري يؤثران

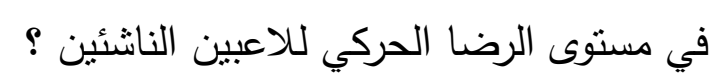

ץ- أي من الأسلوبين المصاحبين للنتريب المهاري أكثر من غير هـ تأثيراً في مستوى الرضا لاعنا

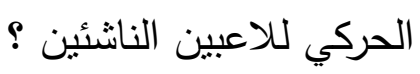




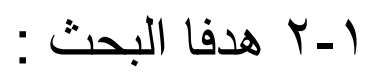

1. الكثف عن اثر التدريب الذهني بالأسلوب المباشر وغير المباشر والاعتيادي في مستوى

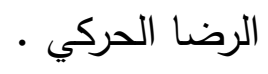

r. الكثف عن الفروق بين مجاميع البحث الثثلاث في الاختبارات البعدية في مستوى الرضا

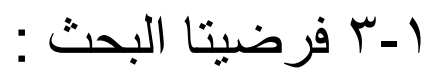

ا ـ يؤثر التدريب الذهني بالأسلوب المباشر وغبر المباشر تأثيراً إيجابياً معنوياً في مستوى الرضا

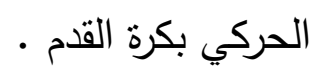

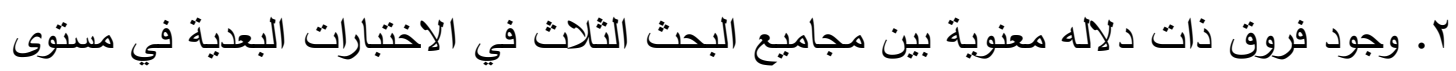

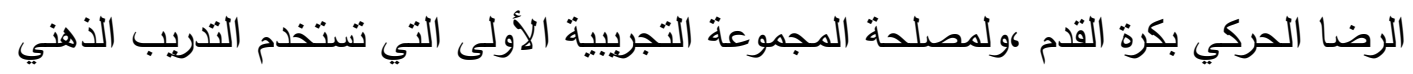

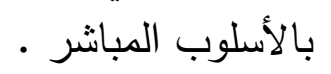

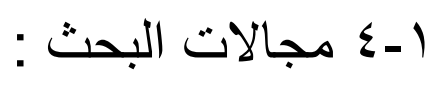

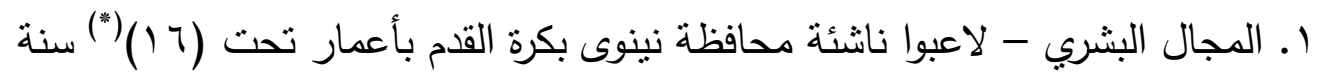

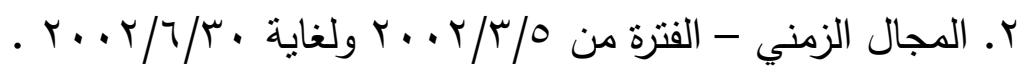

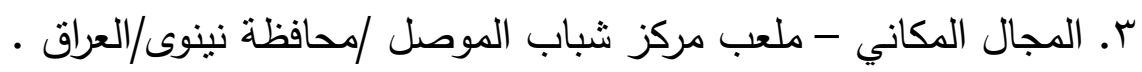

r - الإطار النظري و الدر اسات السابقة :

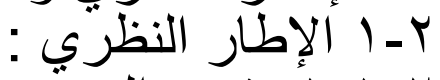

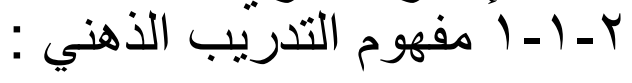

"هو عملية التكرار الذاتي الإرادي لخط سير حركة رياضة الذية معينة ، ويحتوي هذا التصور

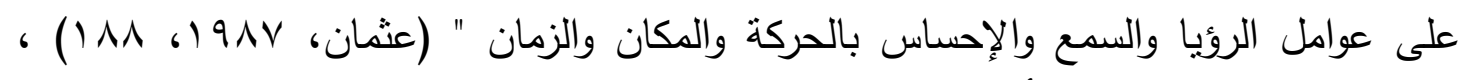

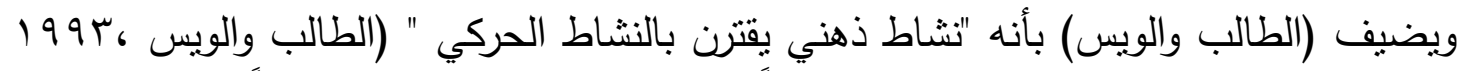

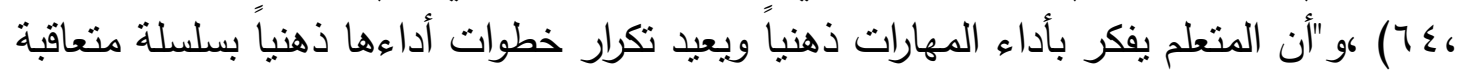

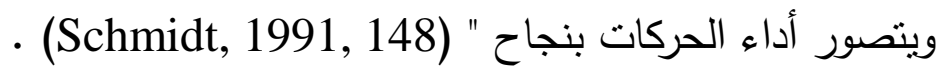

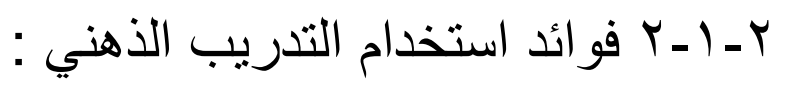

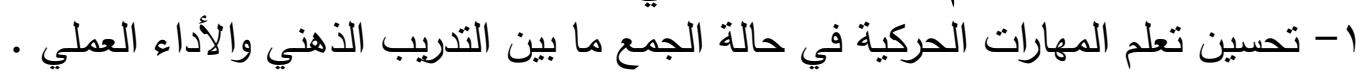

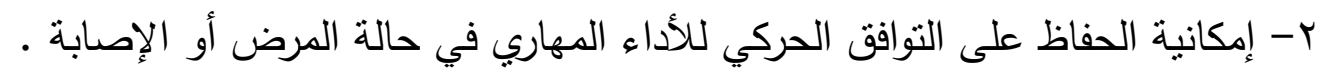

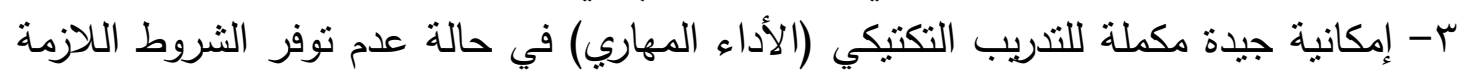

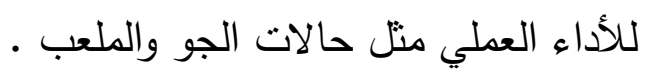

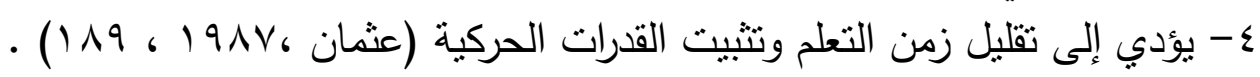




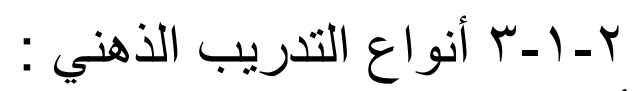

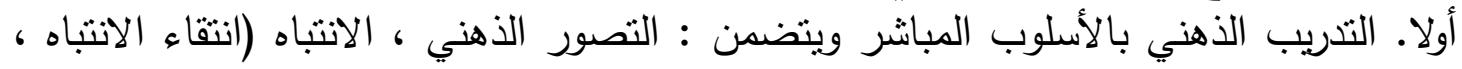

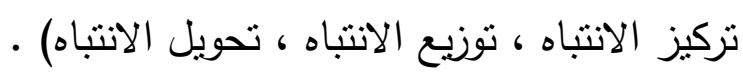

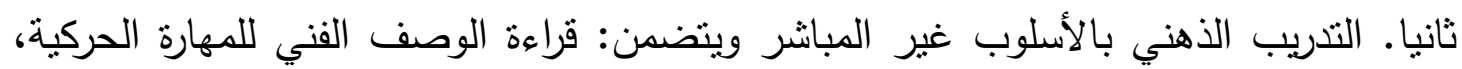

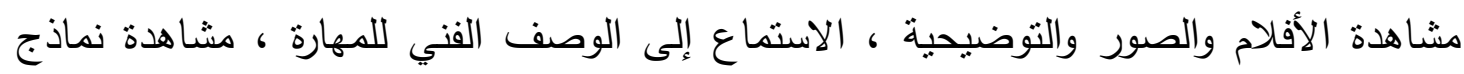

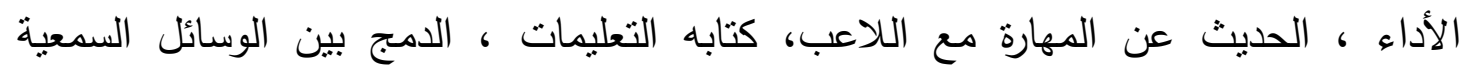

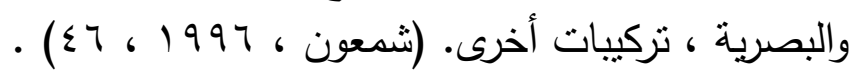

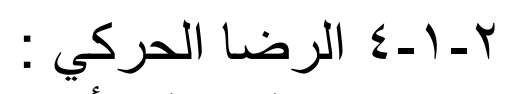

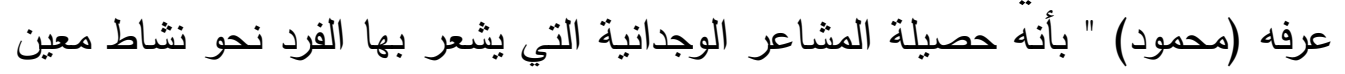

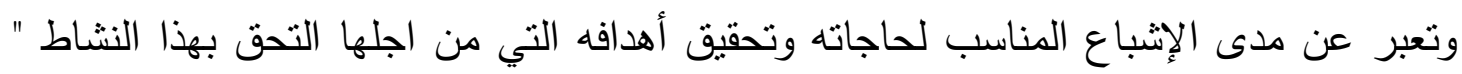

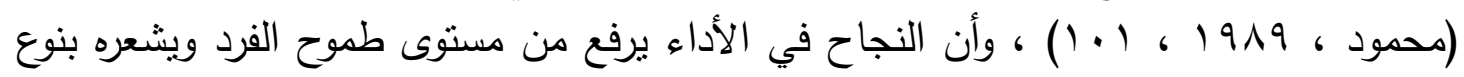

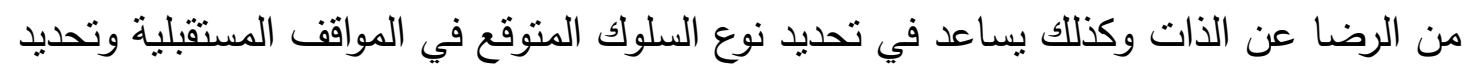

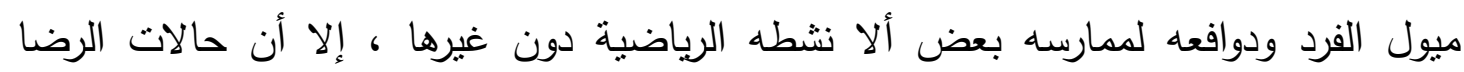

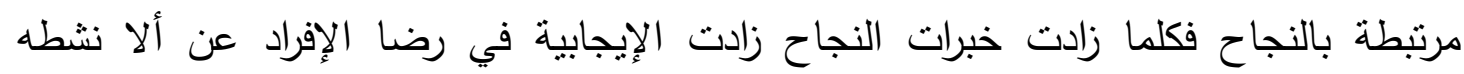

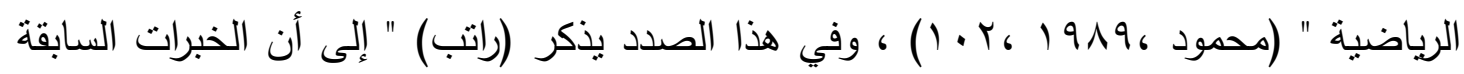

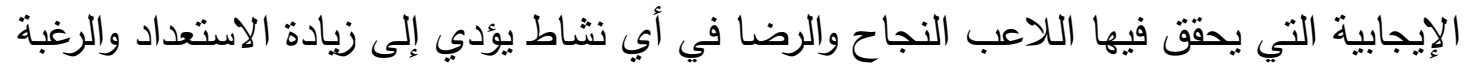

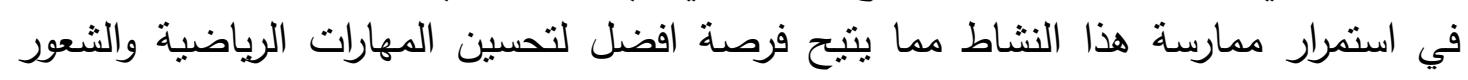

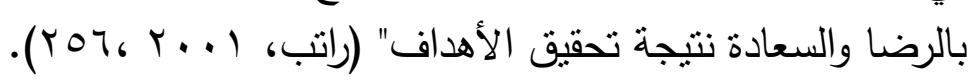

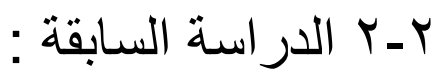

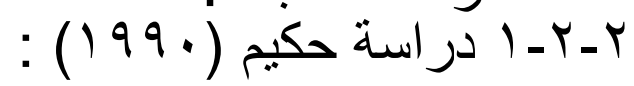

"مؤثرات الرضا الحركي للاعبين الناشئين بمراكز التدريب في جمهورية مصر العربية"

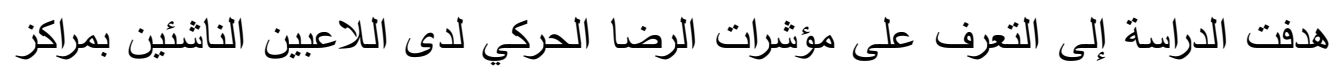

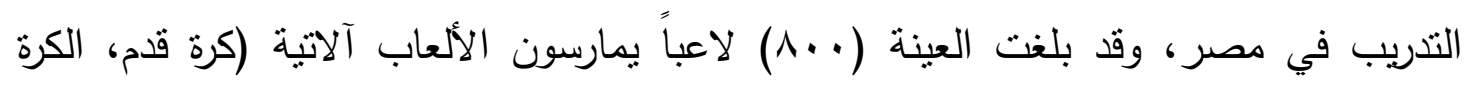

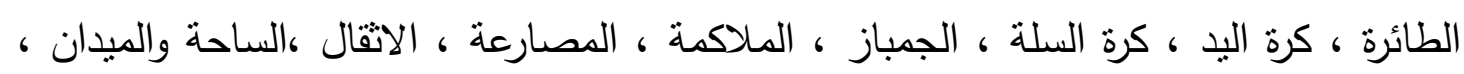

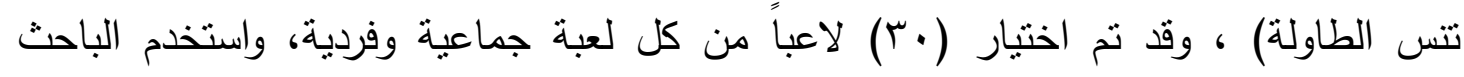
مقياس (تتر) للرضا الحركي وينكون من (•r) فقرة مع ميزان تقدير خماسي، وتوصلت الدارية

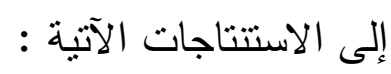
ا- إن مؤشرات الرضا الحركي اتجهت نحو الإيجابية بوجه عام لدى النانشئين في جميع مراكز التدريب إن الترات r- هناك فروق دالة إحصائياً في مؤشرات الرضا الحركي الإيجابية بين اللاعبين الناشئين في

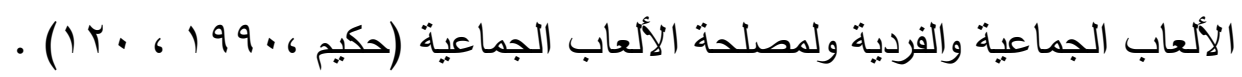


r - ا منهج البحث : أستخدم المنهج التجريبي لملاءمته لطبيعة وأهداف البحث :

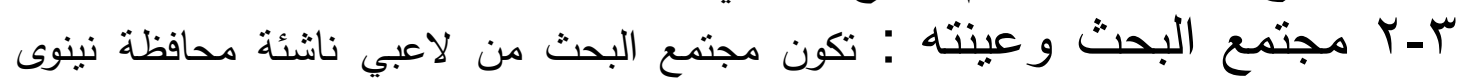

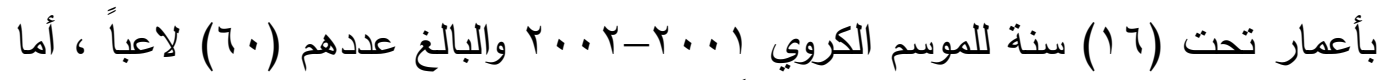

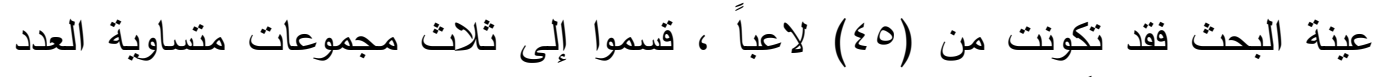

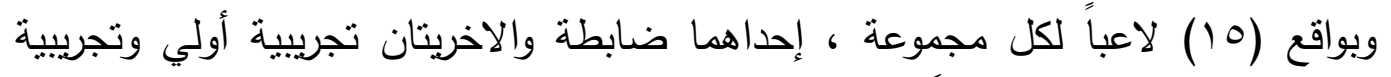

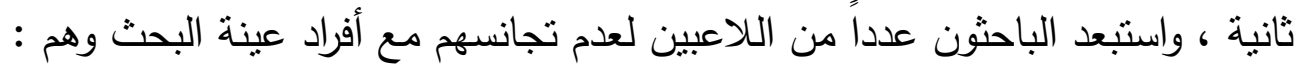

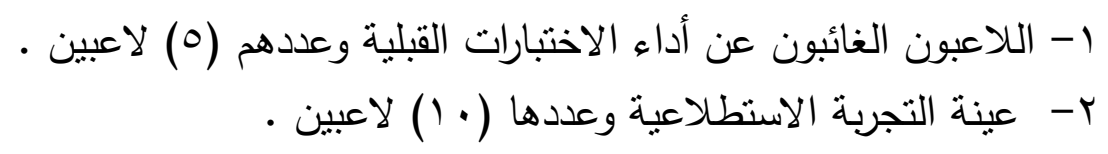
ب-r تكافؤ مجاميع البحث: :

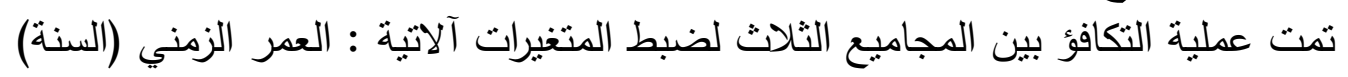

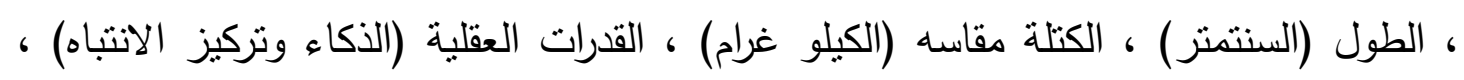

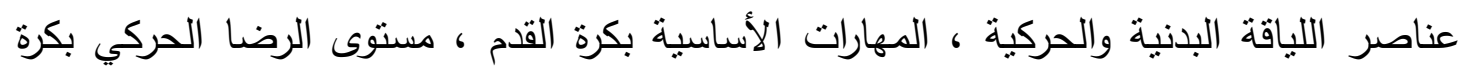
القدم •

ثم قام الباحثون بإجراء عملية التكافؤ بين مجاميع البحث الثلاث في بعض التهات العمليات

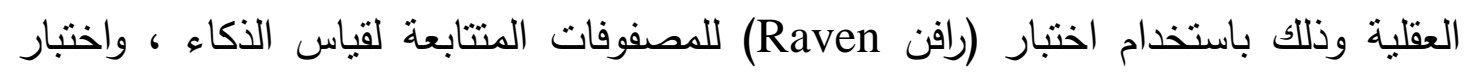

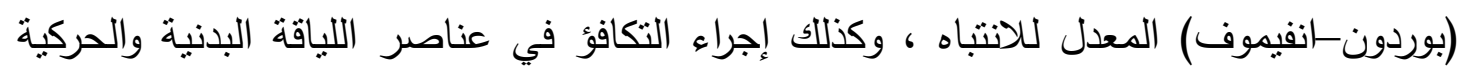

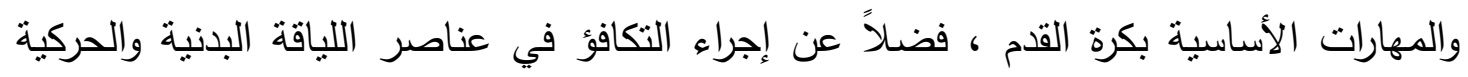

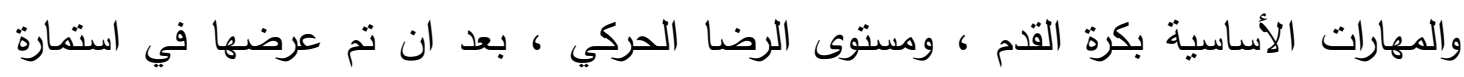

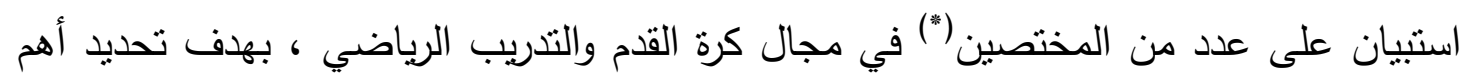

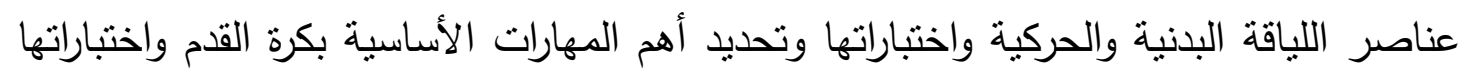

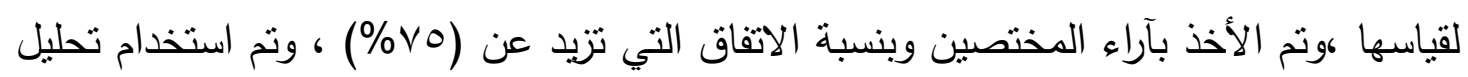

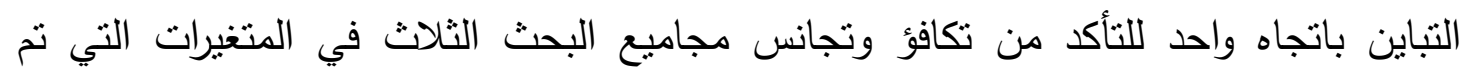

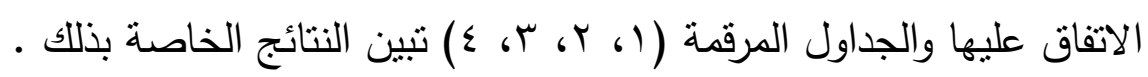

( أ.د. أحمد سعيد احمد - كلية التربية الرياضية - جامعة بغداد

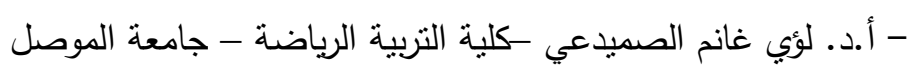

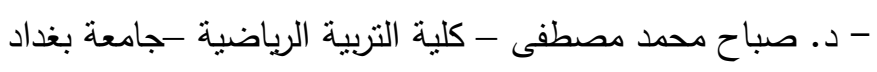

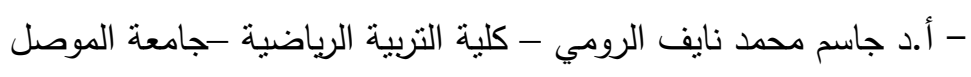

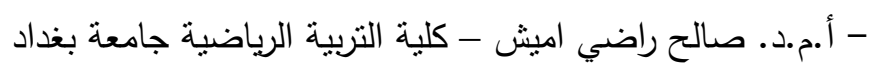
- أ.م.د. مكي محمود حسين الراوي - كلية التربية الرياضية - جامعة المبية الموصل 


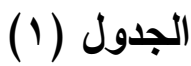

يبين تحليل التباين بين مجموعات البحث الثلاث في كل من (العمر،الطول ،الكتّة ، الأكاء، تركيز الاتتباه)

\begin{tabular}{|c|c|c|c|c|c|c|}
\hline ق المحتسبة (ف) & متوسط المربعات & مجموع المريعات & الحرية & مصدر التباين & المتغيرات & $ت$ \\
\hline \multirow{2}{*}{$1,7 \leqslant \Lambda$} & תTז, & $1, r \leqslant 0$ & r & بين المجموعات & \multirow{2}{*}{ العمر / سنة } & \multirow{2}{*}{1} \\
\hline & $\cdot$, rVA & 10,174 & $\varepsilon r$ & داخل المجموعات & & \\
\hline \multirow{2}{*}{1,0} &., .10 & $\cdot, \cdot r q$ & r & بين المجموعات & \multirow{2}{*}{ الطول / سم } & \multirow{2}{*}{ r } \\
\hline & $\cdot, \cdot 1$ & $\cdot, \varepsilon r$. & $\varepsilon r$ & داخل المجموعات & & \\
\hline \multirow{2}{*}{$\cdot, Y Y T$} & Tr, 107 & $\left.\sum \varepsilon, M Y\right)$ & r & بين المجموعات & \multirow{2}{*}{ الكتلة / كغم } & \multirow{2}{*}{$r$} \\
\hline & $99, \leqslant \leqslant \wedge$ & $\sum 1 \vee 4, \vee 9 q$ & $\leqslant r$ & داخل المجموعات & & \\
\hline \multirow{2}{*}{ צחז, • } & $11,77 V$ & צזוז,Tr & r & بين المجموعات & \multirow{2}{*}{ الذكاء / درجة } & \multirow{2}{*}{$\varepsilon$} \\
\hline & $r \varepsilon, \tau \wedge r$ & $1 \leq 0,777$ & $\varepsilon r$ & داخل المجموعات & & \\
\hline \multirow{2}{*}{$\cdot, \cdot 11$} & rAY $\leqslant \Lambda, \cdot V 0$ & $07 \leq 97,1 \leq 9$ & $r$ & بين المجموعات & \multirow{2}{*}{ | تركيز الانتباه / } & \multirow{2}{*}{0} \\
\hline & $r \leqslant \vee q \cdot \leqslant \vee, r r q$ & $1 . \varepsilon 1199 \wedge \varepsilon, \cdot 49$ & $\varepsilon r$ & داخل المجموعات & & \\
\hline
\end{tabular}

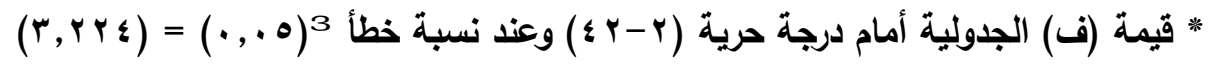

يتبين من الجدول (1) عدم وجود فروق ذات دلالة معنوية بين المجاميع الثلاث في كل من (العمر ، الطول ، الكتلة، الذكاء ، وتركيز الانتباه) وهذا يشير إلى تجانس مجاميع البحث

وتكافؤها في تللك المتغيرات .

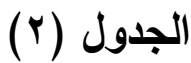

يبين تكافؤ مجاميع البحث في عناصر اللياقة البذنية والحركية المختارة بكرة القدم

\begin{tabular}{|c|c|c|c|c|c|}
\hline قالمتسبة (ف) & متوسط المريعات & مجموع المربعات & لدرجات & مصدر التباين & الاختبارات البدنية(") \\
\hline \multirow{2}{*}{$\cdot, \varepsilon \emptyset$} & $\cdot, r q Y$ & $\cdot, 0 \wedge r$ & r & بين المجموعات & \multirow{2}{*}{ القوة الانفجارية للاطراف } \\
\hline & $\cdot, V_{1}$ & rq,Ar & $\leqslant r$ & داخل المجموعات & \\
\hline \multirow{2}{*}{$\cdot, \wedge \wedge 9$} & 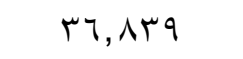 & VT,TVA & r & بين المجموعات & \multirow{2}{*}{ للأطراف السفلى / سم الانفجارية } \\
\hline & $\varepsilon 1, \varepsilon 11$ & $1 V r 9,074$ & $\varepsilon r$ & داخل المجموعات & \\
\hline \multirow{2}{*}{$\cdot, 17 \varepsilon$} & $1, \wedge T \vee$ & $r, v \Gamma \varepsilon$ & r & بين المجموعات & \multirow{2}{*}{ مطاولة عضلات } \\
\hline & 11,817 & $\sum \vee 9, \leqslant 77$ & $\varepsilon r$ & داخل المجموعات & \\
\hline \multirow{2}{*}{$\cdot, \wedge 99$} & • & $\cdot$, YTV & r & بين المجموعات & \multirow{2}{*}{ | السرعة الانتقالية | } \\
\hline & $\cdot, 1 \leq 9$ & T, YTV & $\leqslant r$ & داخل المجموعات & \\
\hline
\end{tabular}

(") جميع الاختبارات مقننه وحسب المصادر العلمية في التدريب الرياضي 


\begin{tabular}{|c|c|c|c|c|c|}
\hline قالمتسبة (ف) & متوسط المربعات & مجموع المريعات & لدرجات & مصدر التباين & الاختبارات البدنية(") \\
\hline \multirow{2}{*}{$r, \varepsilon \cdot \varepsilon$} & $1098, .19$ & MI9ะ, IVA & $r$ & بين المجموعات & \multirow{2}{*}{ مطاولة عامة / دقيقة } \\
\hline & ฯฯร, & rVq.r, ธฯт & $\varepsilon r$ & داخل المجموعات & \\
\hline \multirow{2}{*}{$\cdot, 1 \leq \varepsilon$} & V, YYY & $1 \leqslant, \leqslant \leqslant \varepsilon$ & $r$ & بين المجموعات & \multirow{2}{*}{ مطاولة السرعة / ثانية } \\
\hline & $0 ., 1 \leq$. & TI. $0, \wedge T V$ & $\varepsilon r$ & داخل المجموعات & \\
\hline \multirow{2}{*}{$\cdot, \cdot 11$} & $\cdot, \cdots 0$ & $\cdot, \cdot 1 \cdot$ & r & بين المجموعات & \multirow{2}{*}{ الرشاقة / ثانية } \\
\hline & $\cdot, \leqslant 09$ & $19, r 09$ & $\varepsilon r$ & داخل المجموعات & \\
\hline \multirow{2}{*}{$\cdot, 110$} & $r, r q$. & $\varepsilon, 0 \vee 9$ & $r$ & بين المجموعات & \multirow{2}{*}{ المرونة / سم } \\
\hline & $r$. & 149,999 & $\varepsilon r$ & داخل المجموعات & \\
\hline
\end{tabular}

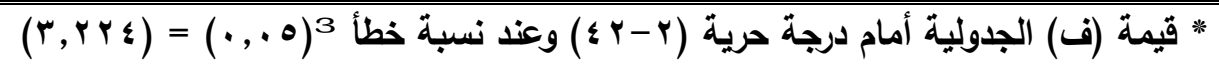

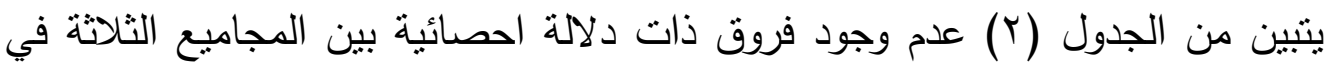
عناصر اللياقة البدنية والحركية المختارة وهذا يشير الى ان المجاميع الثلاثثة متكافئة في العناصر البدنية والحركية .

\section{الجدول (r) (ب) (ب)}

يبين تكافؤ مجاميع البحث الثلاث في المهارات الاساسية المختارة بكرة القدم

\begin{tabular}{|c|c|c|c|c|c|}
\hline ق المحتسبة (ف) & متوسط المربعات & مجموع المريعات & الحرية & مصدر التباين & الاختبارات المهارية(") \\
\hline \multirow{2}{*}{$\cdot, V Y \wedge$} & 1,110 & r, & $r$ & بين المجموعات & \multirow{2}{*}{ اختبار الدحرجة / ثانية } \\
\hline & $r, \sum q r$ & $1 \cdot \varepsilon, 71$ & $\varepsilon r$ & داخل المجموعات & \\
\hline \multirow{2}{*}{$\cdot, r \cdot 4$} & $1 \cdot, A Y K$ & $r 1, T \leq \varepsilon$ & $r$ & بين المجموعات & \multirow{2}{*}{ اختبار المناولة القصيرة } \\
\hline & ro, r $\varepsilon$. & $1 \leqslant \wedge \varepsilon, Y \Psi \vee$ & $\varepsilon r$ & داخل المجموعات & \\
\hline \multirow{2}{*}{$\cdot, 0 Y 4$} & $1 T, \cdot T V$ & Tצ,ITr & $r$ & بين المجموعات & \multirow{2}{*}{ المتنبار المناولة } \\
\hline & TE,AYO & $1 \cdot \sum r, 77 V$ & $\varepsilon r$ & داخل المجموعات & \\
\hline \multirow{2}{*}{$\cdot, 19 \varepsilon$} & $V, \cdot V Y$ & $1 \leqslant, 1 \leqslant \varepsilon$ & $r$ & بين المجموعات & \multirow{2}{*}{ اختبار المناولة الطويلة / منز } \\
\hline & r4,0.. & 10r & $\varepsilon r$ & داخل المجموعات & \\
\hline \multirow{2}{*}{ גוג } & $\cdot, 907$ & 1,911 & $r$ & بين الدجموعات & \multirow{2}{*}{ | اختبار الإخماد } \\
\hline & $r, Y \ldots$ & $1 \cdot 9, r \ldots$ & $\varepsilon r$ & داخل المجموعات & \\
\hline \multirow{2}{*}{$\cdot, \cdot 114$} & $\cdot, Y T V$ & .,OH & $r$ & بين المجموعات & \multirow{2}{*}{ | اختبار التهديف } \\
\hline & $1, \leqslant$ \% & $7 .$, YTV & $\varepsilon r$ & داخل المجموعات & \\
\hline \multirow{2}{*}{$\cdot, \wedge \vee$. } & rIr,. 19 & $\varepsilon r \neg, I \vee \wedge$ & $r$ & بين الدجموعات & \multirow{2}{*}{ اختبار تتطيط الكرة في } \\
\hline & $r \leqslant \varepsilon, q 1 \varepsilon$ & $1 . \nvdash \wedge \neg, \varepsilon \ldots$ & $\varepsilon r$ & داخل المجموعات & \\
\hline \multirow{2}{*}{ 品 } &., 107 & $\cdot, \Gamma 11$ & $r$ & بين المجموعات & \multirow{2}{*}{ اختبار نطح الكرة / } \\
\hline & T, QTV & Mr, & $\varepsilon r$ & داخل المجموعات & \\
\hline \multirow{2}{*}{$\cdot, \cdot \leq r$} & $\cdot, \cdot V Y$ & $\cdot, 1 \leq \varepsilon$ & $r$ & بين المجموعات & \multirow{2}{*}{ |ختبار الرمية الجانبية / } \\
\hline & $1, V \backslash V$ & $V Y, 1 \ldots$ & $\varepsilon r$ & داخل المجموعات & \\
\hline
\end{tabular}

(") جميع الاختبارات مقننه وحسب المصادر العلمية في كرة القدم 


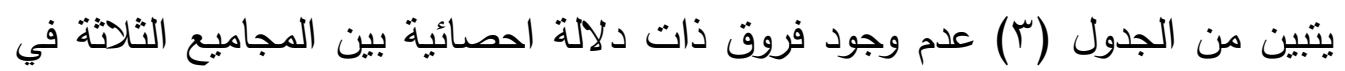
الاختبارات المهارية ، مما يشير الى تكافؤ مجاميع البحث الثناث في المهارات الاساسية بكرة

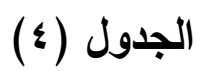

يبين تكافؤ مجاميع البحث الثلاث في مستوى الرضا الحركي للمهارات الأساسية بكرة القام

\begin{tabular}{|c|c|c|c|c|c|}
\hline قل (فتسبة & متوسط المربعات & مجموع المربعات & الحرية & مصدر التباين & الاختبارات المهارية(") \\
\hline \multirow{2}{*}{ •, ror } & $\{\wedge, 90\}$ & $9 \vee, 911$ & $r$ & بين المجموعات & \multirow{2}{*}{ مقياس الرضا الحركي } \\
\hline & $1 \Gamma \wedge, \lambda \cdot 7$ & OATQ,人TV & $\varepsilon r$ & داخل المجموعات & \\
\hline
\end{tabular}

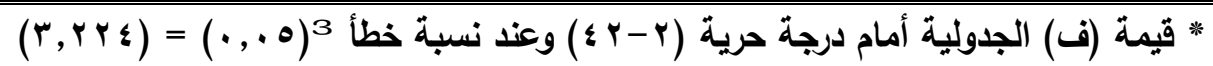

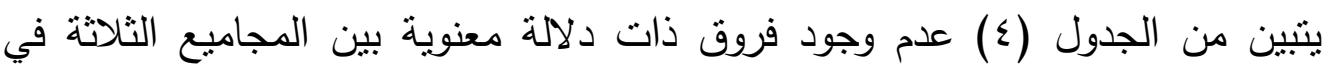

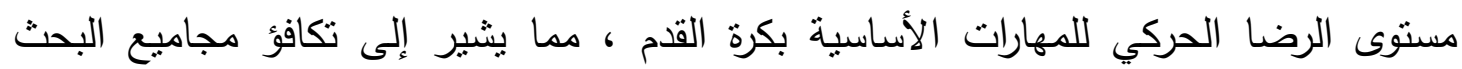

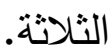

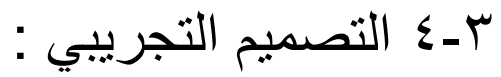
استخدم الباحثون التصميم التجريبي الذي يطلق علية اسم "تصميم المجموعات المتكافئة

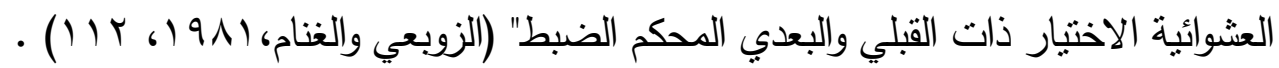

$$
\begin{aligned}
& \text { بـ أدوات البحث : } \\
& \text { ا ـ استمارة استبيان } \\
& \text { r. الاختبار والقياس } \\
& \text { r. الملاحظة والتجريب } \\
& \text { ع. مقياس الرضا الحركي }
\end{aligned}
$$

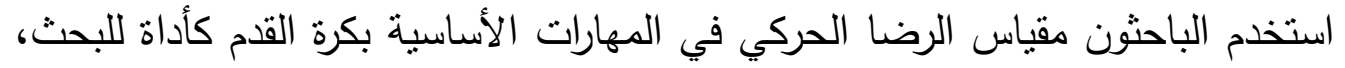

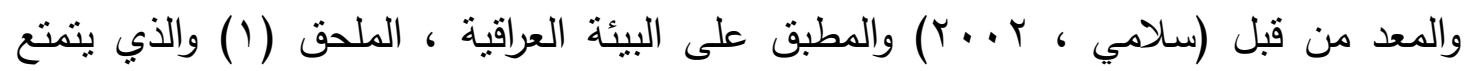

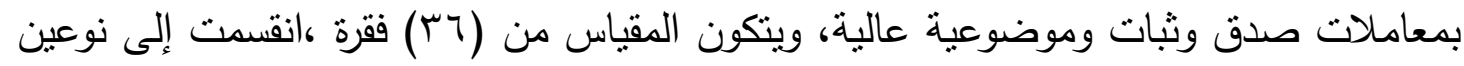

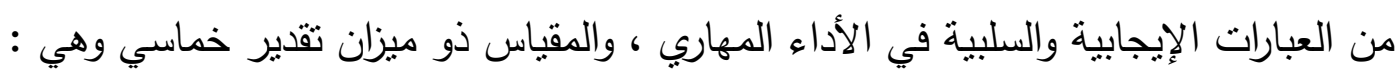

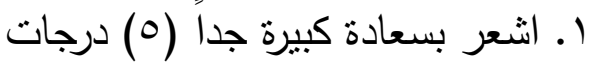

$$
\begin{aligned}
& \text { r. انشعر بسعادة كبيرة (ع) درجات }
\end{aligned}
$$

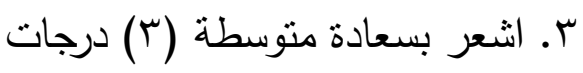

$$
\begin{aligned}
& \text { ع. اشعر بضيق (Y) درجتان } \\
& \text { ه. اشعر بضيق شديد (1) درجة واحدة }
\end{aligned}
$$

(") جميع الاختبارات مقننه وحسب المصادر العلمية في كرة القدم 


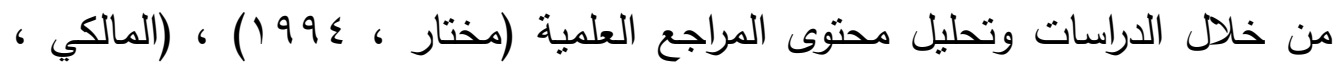

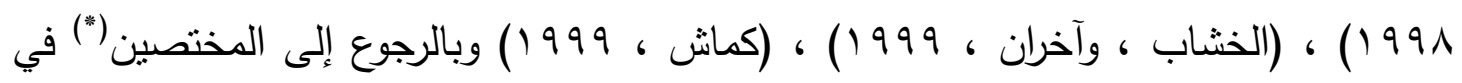
كرة القدم والتدريب الرياضي والتعلم الحركي لاستطلاع آرائهم في مدى صلاحية البرامج التعليمية

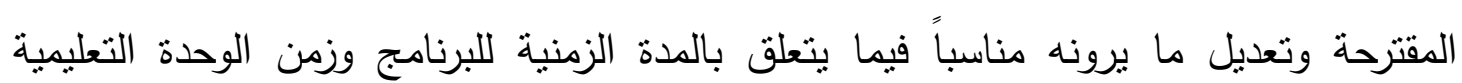

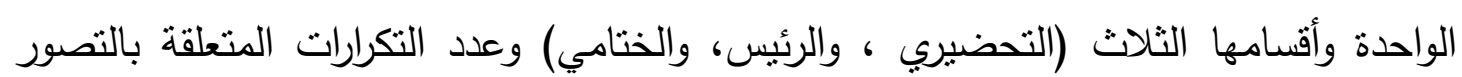

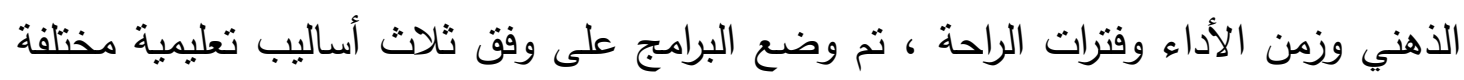
لتعلم وإتقان الدهارات الأساسية بكرة القدم ، ينسجم والخصائص العمرية وميول وقدرات اللاعبين التالين

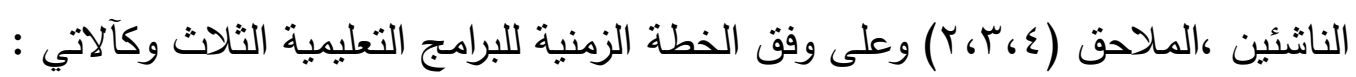

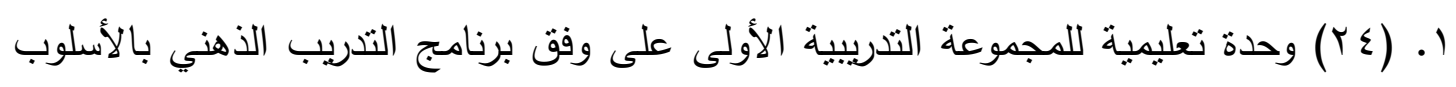

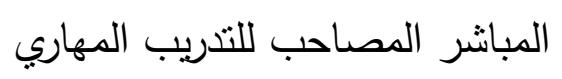

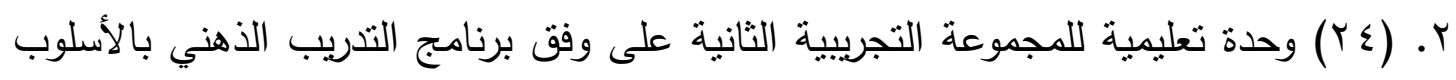
غير المباثر الصصاحب للتثريب المهاري

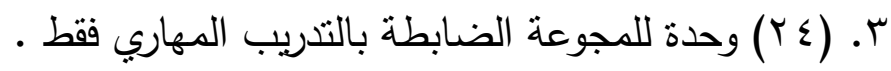

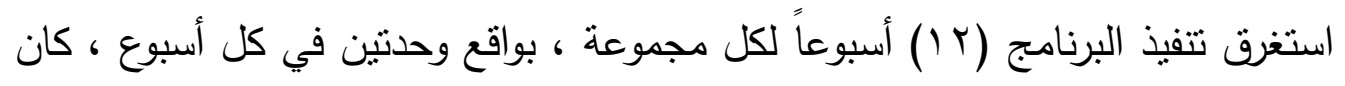
زمن الوحدة التطليمية الواحدة ( •9) دقيقة .

(") - أ.د. احمد سعيد احمد - كلية التربية الرياضية - جامعة بغداد

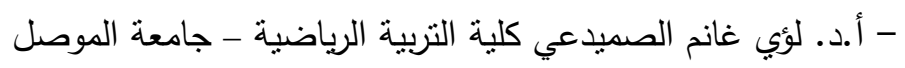
- أ.د. عامر محمد سعودي - كلية التزبية الرياضية - جامعة المباضية - جامعة الموصل

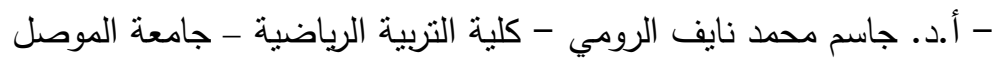

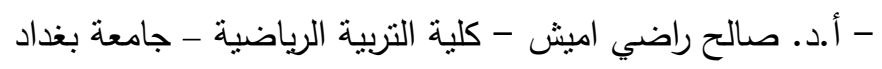
- أ.م.د. خالد عبدالمجيد الخطيب - كلية التربية الرياضية - جامعة المباضية الموصل - أ.م.د. مكي محمود حسين الراوي - كلية التربية الرياضية - جامعة الموصل 
V- التجربة الاستطلاعية للبر امج التعليمية الثلاثة :

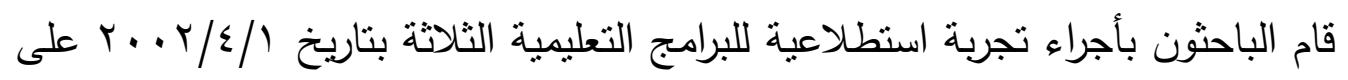
عينة مكونة من (· () لاعبين من مجتمع البحث الأصلي وذلك بهدف : 1- التعرف على مدى امكانية تطبيق البرامج التعليمية r- تلافي الأخطاء التي يمكن أن تحدث في أثناء تطبيق البرامج التعليمية .

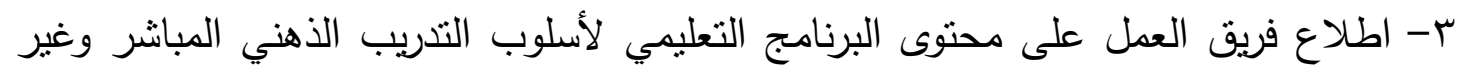
· المباشر

ع - التعرف على الوقت اللازم لتطبيق فقرات الوحدات التعليمية الدقترحة .

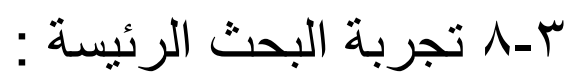

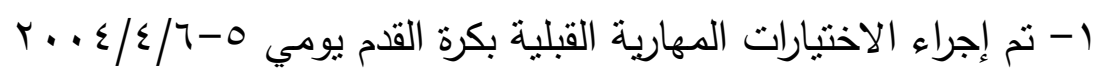

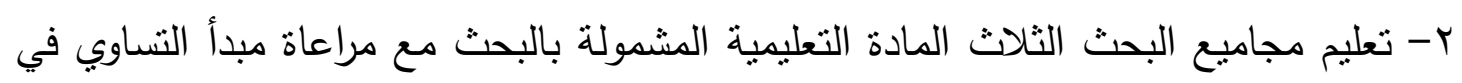

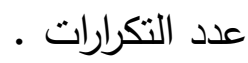

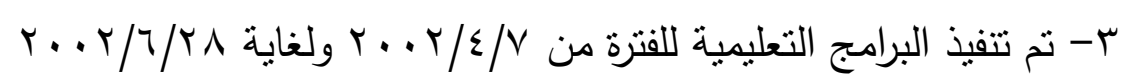
ع- تم تطبيق مقياس الرضا الحركي في المهارات الأساسية بكرة القدم على مجاميع البحث

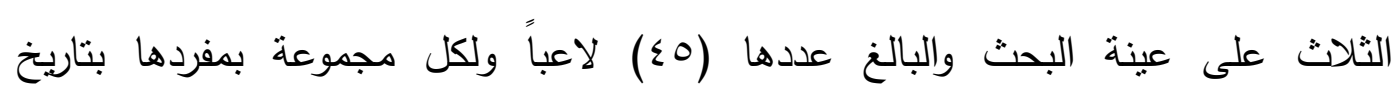

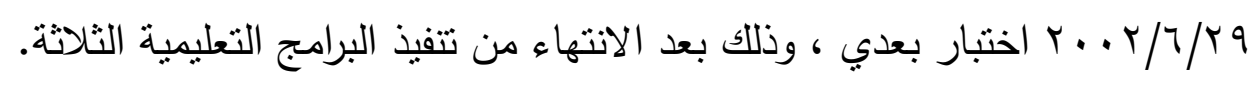

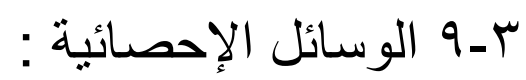

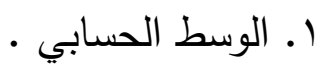

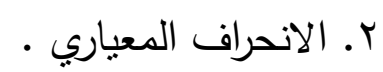
r. اختبار" ت" لـتوسطين حسابين مرتبطين ولعينتين متساويتين .

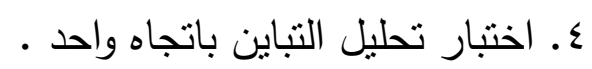

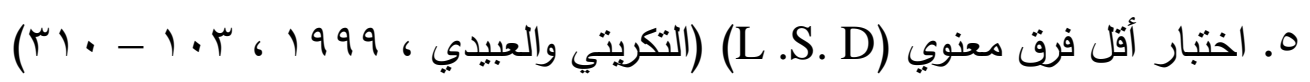


ع - عرض النتائج ومناقشتها : ع عرضان

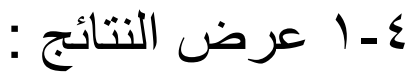

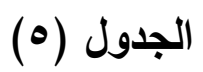

يبين اختبار (ت) للاختبارين القبلي والبعدي لمجموعات البحث الثلاثة في مقياس الرضا الحركي

\begin{tabular}{|c|c|c|c|c|c|}
\hline \multirow{2}{*}{ قيمة (ت) } & \multicolumn{2}{|c|}{ الاختبار البعدي } & \multicolumn{2}{|c|}{ الاختبار القبلي } & \multirow{2}{*}{ الاختبارات المهارية } \\
\hline & $\varepsilon^{r \pm}$ & بَس & $\varepsilon^{\prime \pm}$ & اس & \\
\hline rA, 701 & $7, \leqslant 1 \leqslant$ & $|v|$ & 9,00 & $111, \cdot 7 V$ & التجريبية الأولى \\
\hline rr, rqu & $\Lambda, \varepsilon \leqslant r$ & אזו, •דו & $1 \cdot, v 07$ & מro, . 1. & التجريبية الثانية \\
\hline$r\urcorner, T \vee 0$ & $11,1 Y \varepsilon$ & lor, r.. & $1 Y, \lambda 17$ & $1.9,7 \ldots$ & التجريبية الثالثة \\
\hline
\end{tabular}

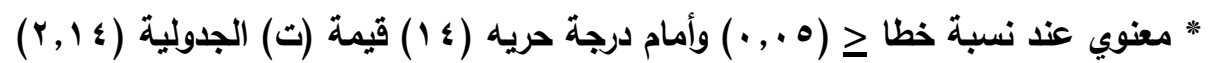

يتبين من الجدول (0) وجود فروق ذات دلالة معنوية بين الاختبارين القبلي والبعدي

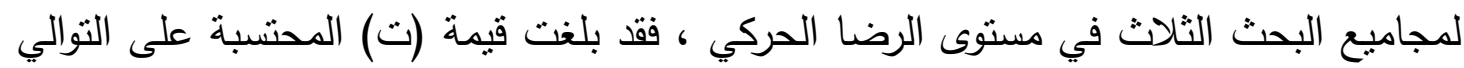

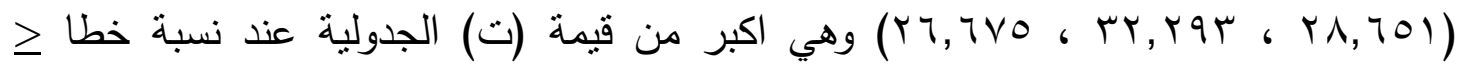

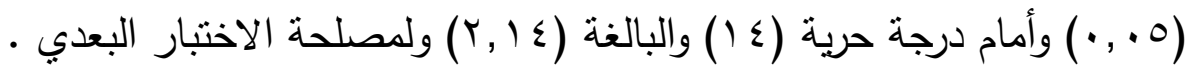

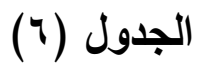

يبين نتائج تحليل التباين لمجموعات البحث في الاختيار البعدي في مقياس الرضا الحركي

\begin{tabular}{|c|c|c|c|c|c|}
\hline قالمتسبة (ف) & متوسط المريعات & مجموع المربعات & لدرجات & مصدر التباين & الاختبارات المهارية \\
\hline \multirow{2}{*}{$17,9 \vee \leqslant$} & & YTVY, MII & r & بين المجموعات & \multirow[t]{2}{*}{ مقياس الرضا الحركي } \\
\hline & Y^, VIV & rr, & $\varepsilon r$ & داخل المجموعات & \\
\hline
\end{tabular}

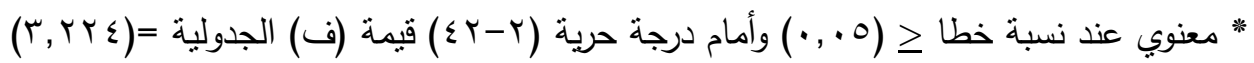

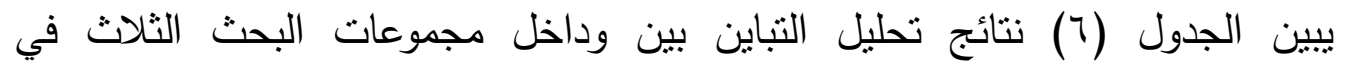

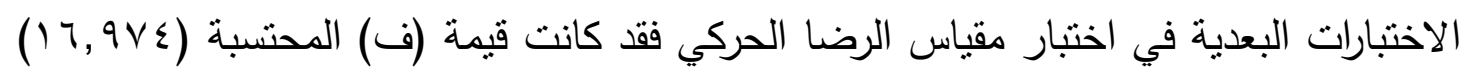

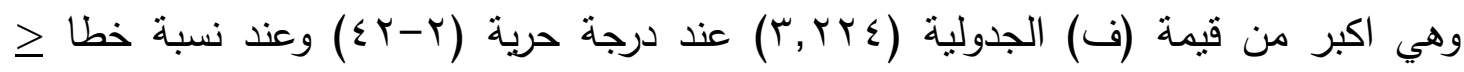
(0. . •) وهذا يدل على وجود فرق معنوي بين مجموعات البحث الثلاث في الاختبار البعدي في

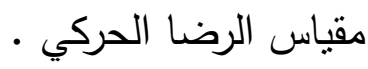

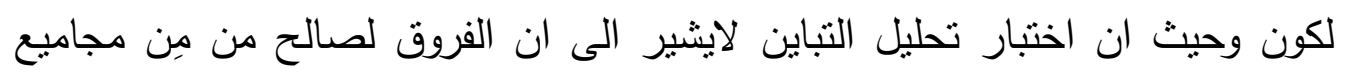

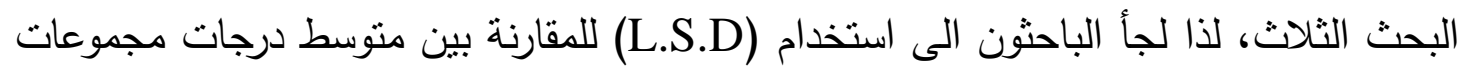

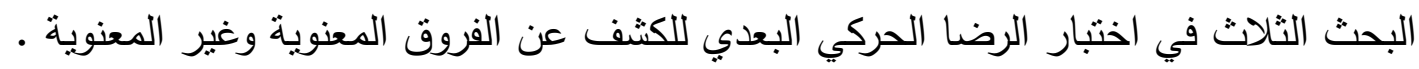




\section{(v) الجدول}

يبين مقارنة الأوساط الحسابية بقيمة (L.S.D) لمجموعات البحث الثلاث في مقياس الرضا الحركي

\begin{tabular}{|c|c|c|c|c|c|}
\hline L.S.D & م.ض & م.ت.ت & م.ت & س & المجاميع \\
\hline \multirow{3}{*}{$7,0 \leqslant 1$} & $* \backslash \wedge, \wedge \ldots$ & $* 1 \cdot, \wedge T \vee$ & - & $|V|$ & م. \\
\hline & *V, & - & - & אזו, •. & م.ت \\
\hline & - & - & - & lor, r.. & م • ض \\
\hline
\end{tabular}

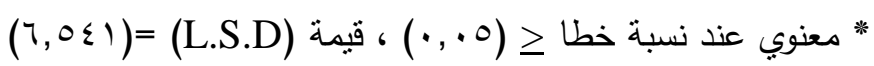

يتبين دن الجدول (V) أن الفرق بين المجموعة التجربيية الأولى والمجموعة التجربيية

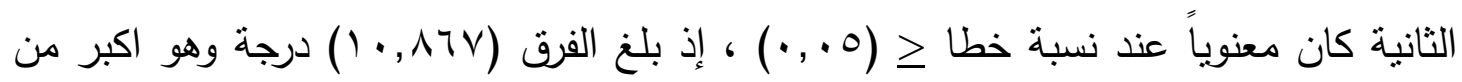

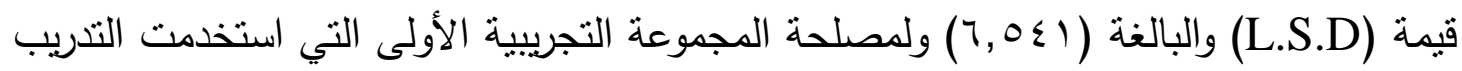
الذهني المباشر المصاحب للتدريب المهاري •

أما الفرق بين المجموعة التجريبية الأولى والمجموعة الضابطة فكان معنوياً عند نسبة

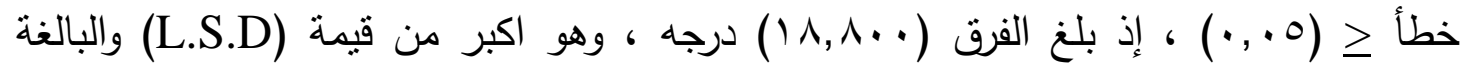
(1,0 (7) ولمصلحة المجموعة التجريبية الأولى التي استخدمت التذريب الذهني المباشر المصاحب للتدريب المهاري .

وكان الفرق بين المجموعة التجريبية الثانية والمجموعة الضابطة معنوياً أيضًاً عند نسبة

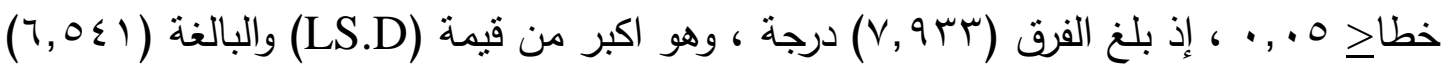
ولمصلحة المجموعة التجريبية الثانية التي استخدمت التذريب الذهني غير المباشر المصاحب • للتدريب المهاري

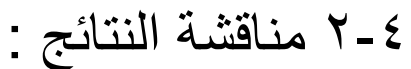

لقد أظهرت نتائج الجدول (0) للاختبارين القبلي والبعدي لمجموعات البحث الثلاث في مستوى الرضا الحركي وجود فروق ذات دلالة معنوية ولمصلحة الاختبارات البعدية ويعزو الباحثون ذلك إلى البرامج التعليمية المطبقة وتأثنرها الإيجابي في زيادة مستوى الرضا الحركي للاعبين في المهارات الأساسية بكرة القدم ، ويتفق ذلك مع ماذكرة " الحياني " من ان الإحساس لهاس بالرضا الحركي نتيجة الاشتراك في العملية التعليمية يؤدي إلى شعور اللاعبين بالسعادة والارتياح لممارسة تللك المهارات الحركية وهذا يودي بدورة إلى التغلب على كثير من الصعوبات التي تواجه اللاعبين عند عملية التدريب ، ويساهم في إثارة الدافعية لديهم نحو الاستمرار في مزاولة ألا نشطه الرياضية ، إذ أن من بين أهم العوامل التي تشاهم في تحقيق الإنجاز الرباضي

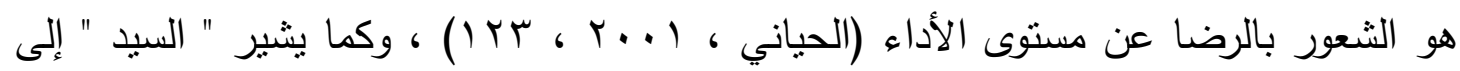
أن كل فرد منا يشعر بالسعادة نتيجة مستوى أدائه لنوع معين من ألا نشطه وتتمية مهارة في 
الأداء (السيد ، 19V9 ، V ) ، وعليه فقد كان للبرنامج التعليمي اثز إيجابي في تعلم المهارات

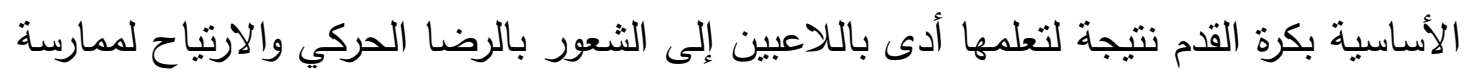

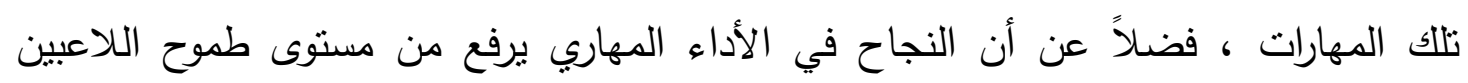

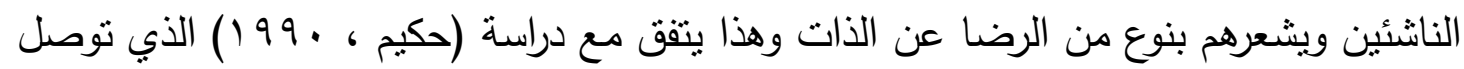

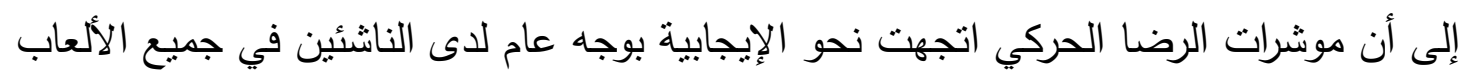
الجماعية في جميع مراكز تدريب الناشئين •

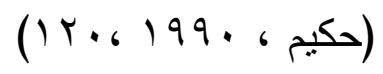

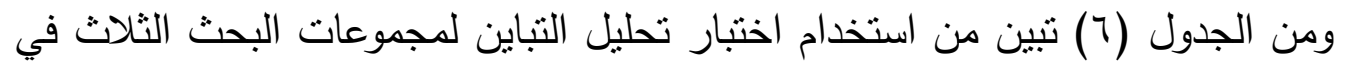

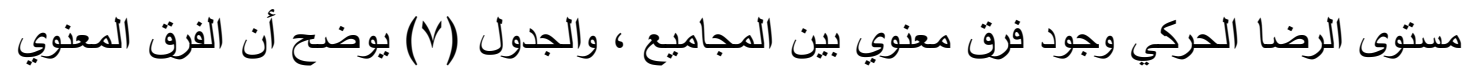

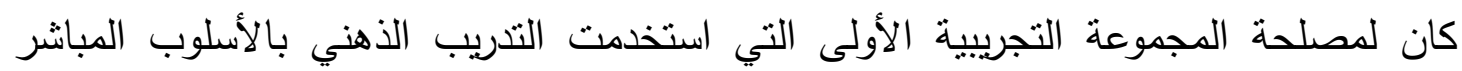

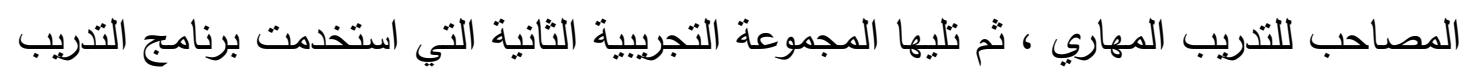

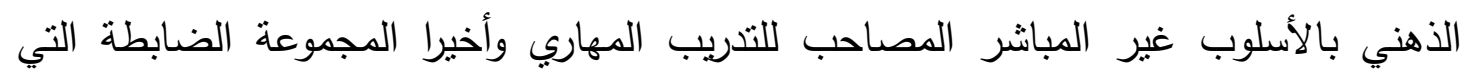

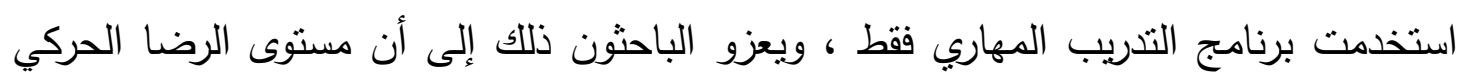

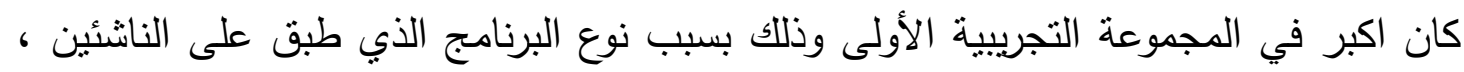

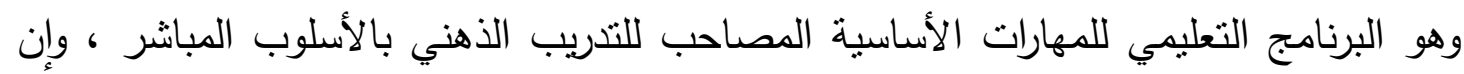

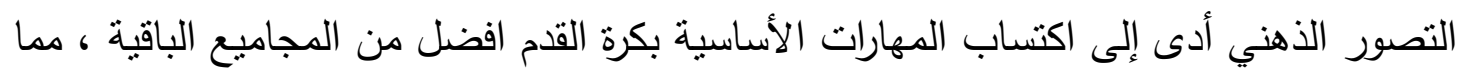

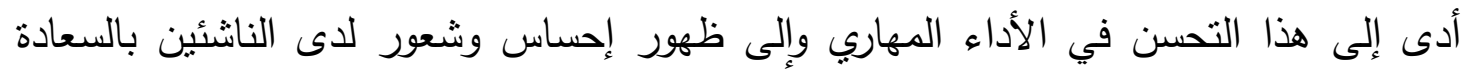

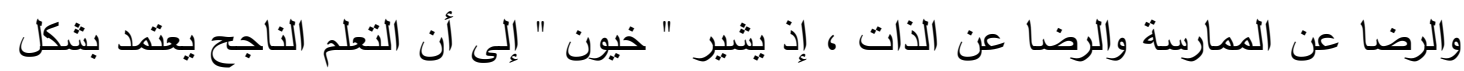

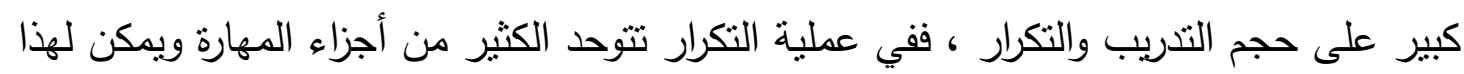

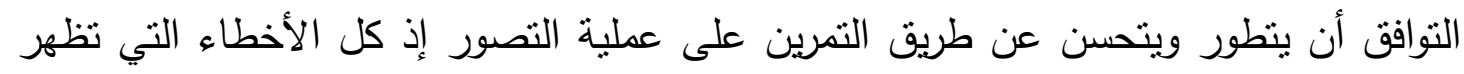

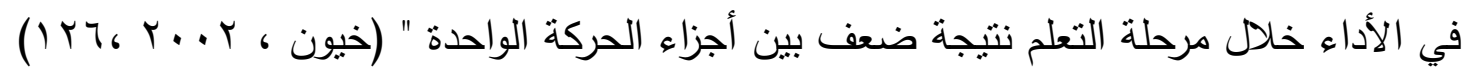

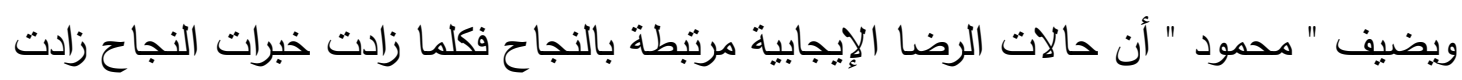

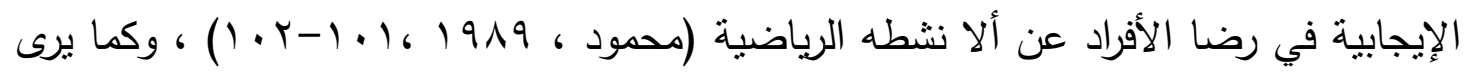
(السادة والبوهي) " أن درجة الرضا عن الدراسة تؤثر في الإنجاز الدراسي اكثر من تأثنير الإنجاز

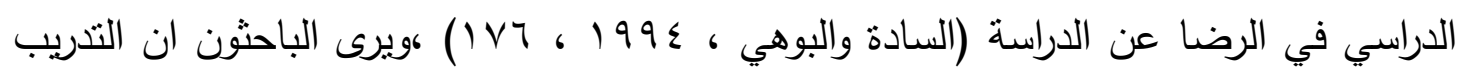

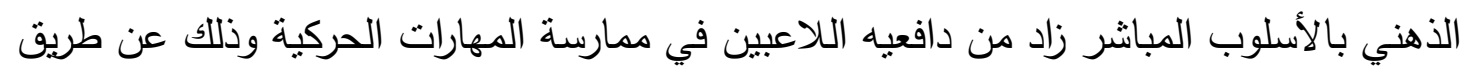

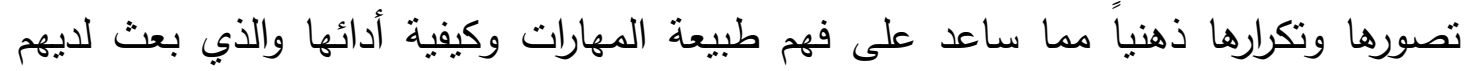

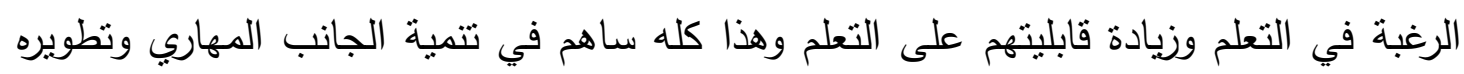

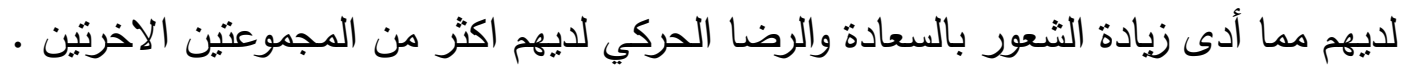




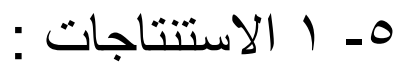

ا ـ إن البرامج التعليمية الثناثة المقترحة ذو تأثثر إيجابي في مستوى الرضا الحركي بكرة القدم .

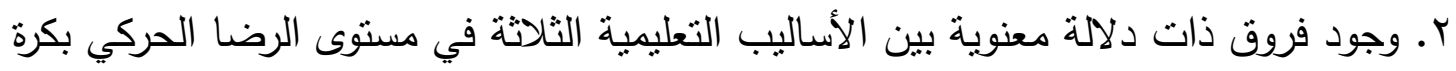

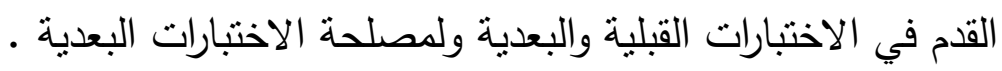

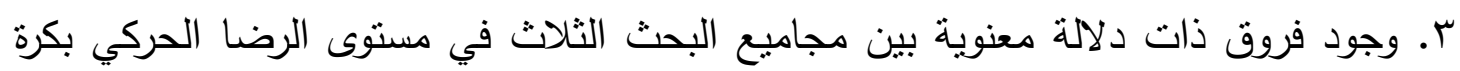

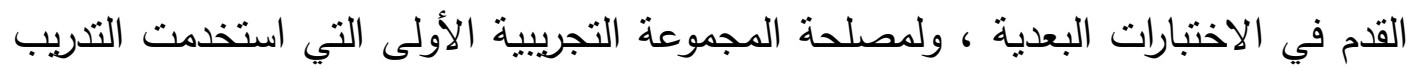

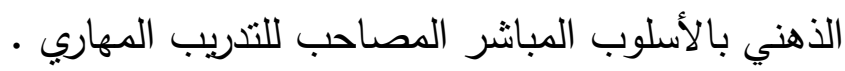
: ب-0 ا ـ نأكيد استخدام التدريب الذهني بأسلوبيه المباشر وغير المباشر في العملية التعليمية والتنريبية للنانشئين بكرة القدم r. اعتماد مقياس الرضا الحركي لقياس مستوى الرضا الحركي في المهارات الأساسية للاعبين

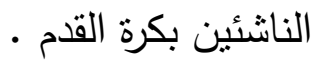
r. الاهتمام بالجانب النفسي والوجداني للاعبين النانشئين عند وضع البرامج التعليمية والتنريبية

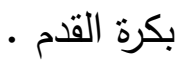
ع. تطبيق برامج تعليمية أخرى للتنريب الذهني في الجانب المهاري والخططي بكرة القدم . 


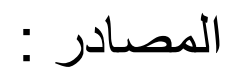

1. التكريتي ، وديع ياسين ، والعبيدي حسن محمد عبد (1999) :- النطبيقات الإحصائية

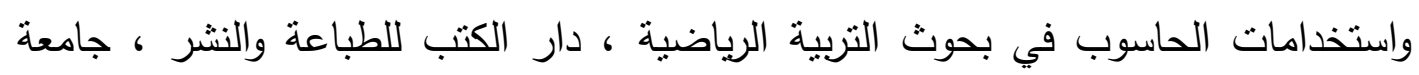
الموصل

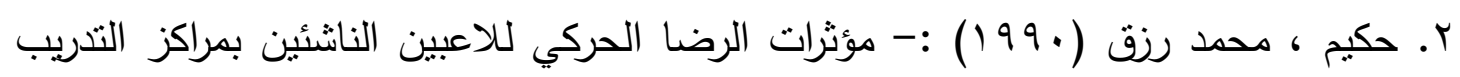

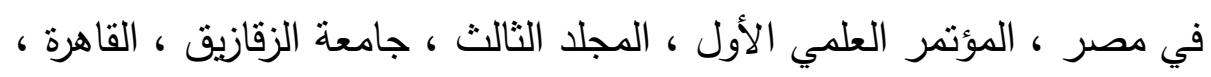

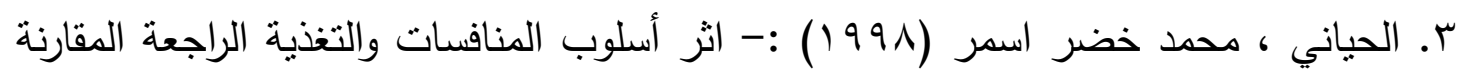

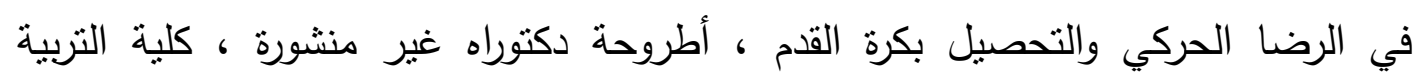
الرياضية ، جامعة الموصل

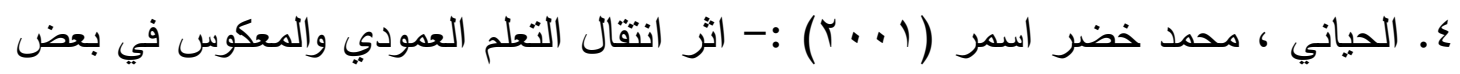

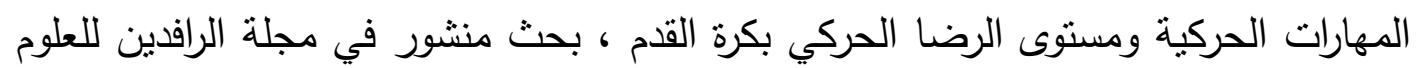

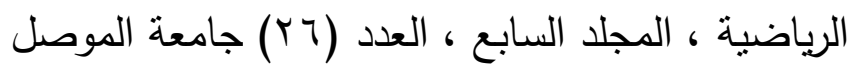

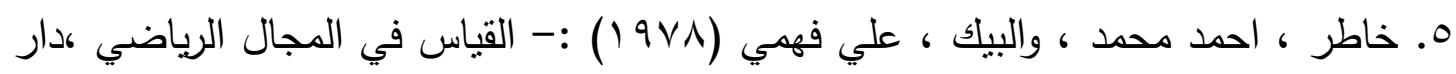
المعارف ، القاهرة 7. الخشاب ، زهير قاسم واخران (999 1) :-كرة القدم ، طن ، دار الكتب للطباعة والنشر ،

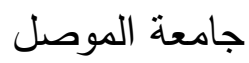
V. خيون ، يعرب (r . . r) :-التعلم الحركي بين المبدأ والتطبيق ومكتب الصخر للطباعة ، بغداد

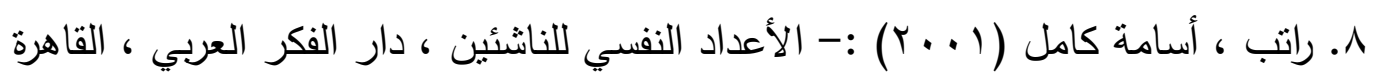

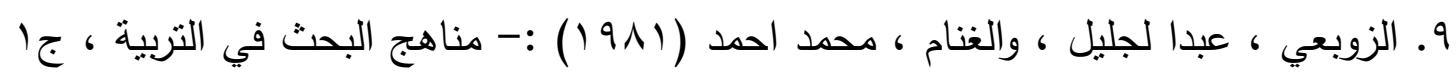

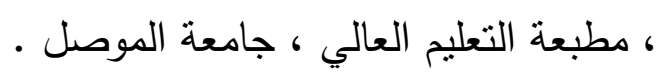

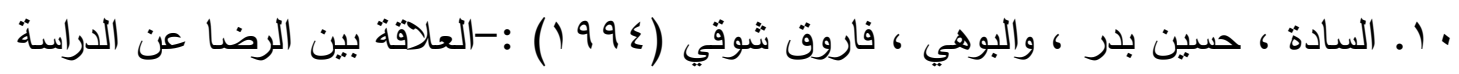

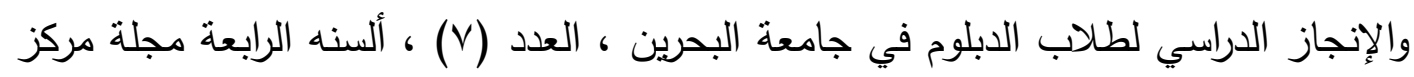

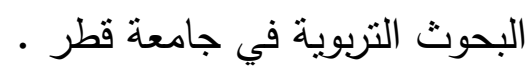

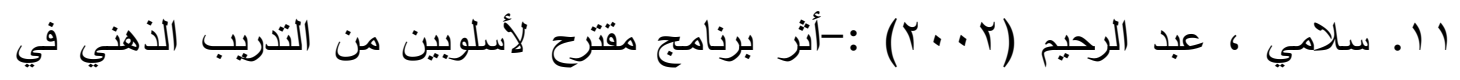

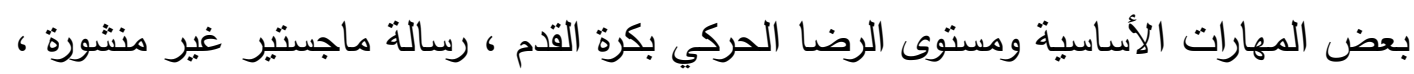
كلية التربية الرياضية ، جامعة الموصل .

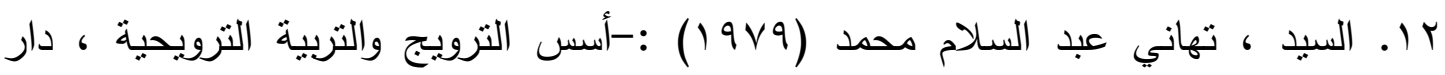
المعارف الإسكندرية ، القاهرة . 
با ا. شمعون ، محمد العربي (7999) :- التدريب العقلي في المجال الرياضي ، طا ، دار الفكر العربي ، القاهرة

ع ا. شمعون ، محمد العربي ، وإسماعيل ، ماجدة محمد (99V I ) :- أثز برنامج مقترح

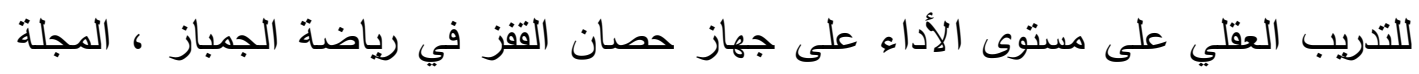
العلمية للتربية البدنية والرياضة ، جامعة حلوان ، القاهرة .

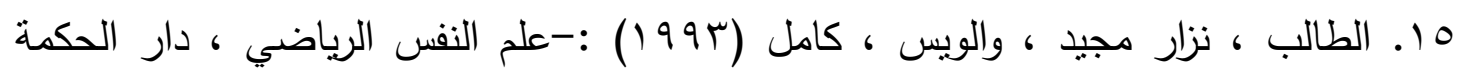

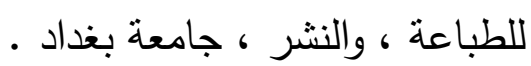

17 (. عثمان ، إسماعيل حامد (.91 (1) :- اثر كل من الطريقتين الكلية والجزئية في تعلم

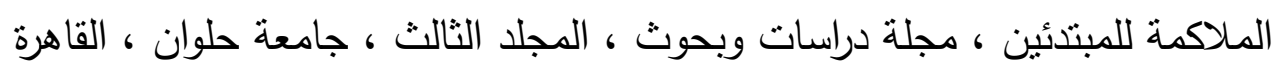

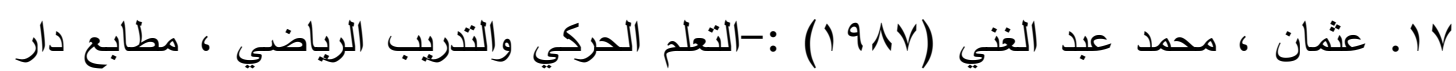

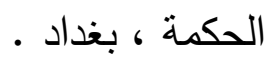

11. كماش ، يوسف لازم (1999) :-المهارات الأساسية في كرة القدم ، (تعليم ،تدريب) ،

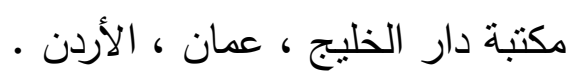

9 1. المالكي ، محمد عبد الحسين (99191) :-أثر التدريب الذهني في تعليم بعض الأردن ، المهارات

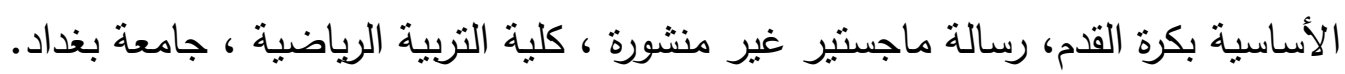

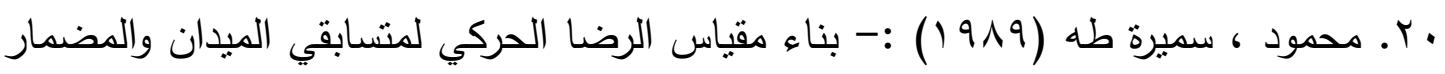

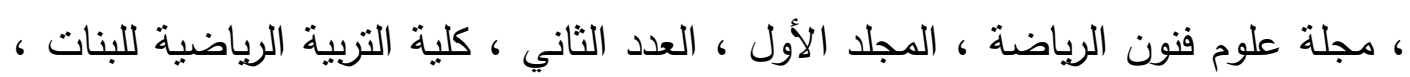
القاهرة (Y. مختار ، حنفي محمود (ع 991) :- الأسس العلمية في التدريب كرة القدم ، طب ، دار

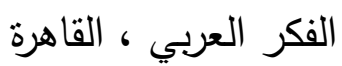

22. Raven J.C (1986):- Standard Progressive Matrices .

23. Schmidt . A . Richard (1991) :- motor Learning \& Profomance, Human Kinetic Books, Illinois . 


\section{الملحق (1)}

\section{مقياس الرضا الحركي}

\begin{tabular}{|c|c|c|c|c|c|}
\hline شضيق & بضيق اشعر & متوسطعة & بسعادة & كبيرة جبعادة & فقرات المقياس \\
\hline & & & & & I الجسم تشعر عندما تنطط الكرة باستمر ار في الهو اء بأجزاء \\
\hline & & & & & r. كيف تشعر عندما تنطط الكرة بالقدمين فقط دون أن تسقط \\
\hline & & & & & r. كيف تشعر عندما تنطط الكرة بالر أس فقط دون ان تسقط \\
\hline & & & & & ع. كيف تشعر عندما تنطط الكرة وأنت تسبر بها \\
\hline & & & & & 0. كيف تشعر عندما تنطط الكرة لاجتياز لاعب منافس \\
\hline & & & & & T. كيف تشعر عندما تخمد كرة قوية بالر أس \\
\hline & & & & & V Y. كيف تشعر عندما تخد كرة بوجه القدم وهي في الهواء \\
\hline & & & & & ^. كيف تشعر عندما تخد كرة بالفخذ والمنافس قريب منك \\
\hline & & & & & 9. كيف تشعر عندما تخمد كرة بالصدر ثم التهديف مباشرة \\
\hline & & & & & • •. كالقدم تشعر عندما تخد كرة بالفذذ ثم التهديف مباشرة \\
\hline & & & & & 11 '. كيف تشعر عندما تخمد كرة بخارج القدم و المنافس قريب \\
\hline & & & & & با. كيف تشعر عندما تخمد كرة بداخل القدم والمنافس بعيد \\
\hline & & & & & rا لـ كيف تشعر عندما تقوم بمناولة قصبرة لزميل مجاور \\
\hline & & & & & ـ ا. كيف المنافعر عندما تقوم بمناولة متوسطة لزميل باتجاه \\
\hline & & & & & 10. كيف تشعر عندما تقوم بمناولة طويلة لزميل خلف \\
\hline & & & & & 17. كيف تثريب منكر عندا تقوم بمناولة بخارج القام والمنافس \\
\hline & & & & & IV الهذف لزميل عندما تقوم بمناولة طويلة من الجانب وأمام \\
\hline & & & & & 11 ـ كيف تشعر عندما تدحرج الكرة باتجاه الهنافس \\
\hline & & & & & 19 ـ كيف تشعر عندما تدحرج الكرة ثم التهديف مباشرة \\
\hline & & & & & • r. كيف تثعر عندما تدحرج الكرة لاجتياز لاعب منافس \\
\hline & & & & & 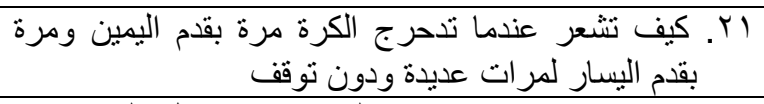 \\
\hline & & & & & ب بارج كيف تشعر عند تدحرج الكرة مرة بداخل القدم ومرة \\
\hline & & & & & بr ـ كيف تثعر عندما الكرة بوجه القدم لمسافة بعيدة \\
\hline & & & & & 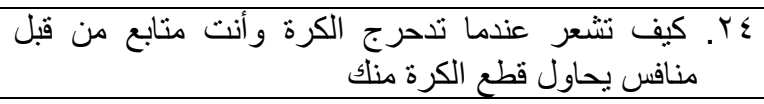 \\
\hline & & & & & Y Y. كيف تشعر عندما تقوم بالتصويب بالقدم غبر المستخدمة \\
\hline
\end{tabular}




\begin{tabular}{|c|c|c|c|c|c|}
\hline شضيق & بضيق & متوسطادة & كبعادة & كبيرة جبادة & فقرات المقياس \\
\hline & & & & & TYY. كيف تشعر عندما تقوم بالتصويب بالقدم أو الرأس \\
\hline & & & & & حارس المرمى عندما تقوم بالتصويب إلى الزاوية البعيدة عن . TV \\
\hline & & & & & Y Y. كيف تشعر عندما تقوم بالتصويب إلى الزاوية القريبة من \\
\hline & & & & & وج. كيف تشعر عندما تقوم بنطح الكرة إلى زميل في موقف \\
\hline & & & & & •r. كيف تشعر عندما تقوم بنطح الكرة إلى زميل في موقف \\
\hline & & & & & آT. كيفً تشعر عندما تقوم بنطح الكرة إلى الجانب من القفز \\
\hline & & & & & r بع. كيفة تشعر عندما تقوم بنطح الكرة من الثبات لمسافة \\
\hline & & & & & rr زميل فتئ موقف صندما تقوم برمية جانبية من وضع الثبات إلى \\
\hline & & & & & ع إلى كيف تشيل في موقدما تقوم برمية جانبية من وضع الحركة \\
\hline & & & & & Tجم كيف تشعة من المنافسين تقوم برمية جانبية إلى زميل بين \\
\hline & & & & & آب. كيف تثعر عندما تقوم برمية جانبية والمنافس و اقف \\
\hline
\end{tabular}




\section{(ب) الملحق}

يبين أقسام الوحدة التعليمية للمجموعة التجريبية الأولى

\begin{tabular}{|c|c|c|c|}
\hline 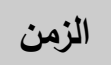 & 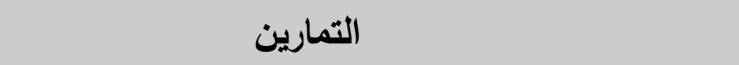 & النشاط & 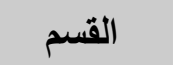 \\
\hline r & 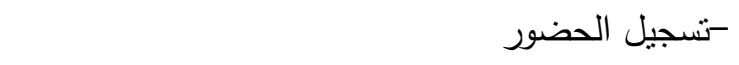 & \multirow{3}{*}{ الإلإحماء العاء الخاص } & \multirow{3}{*}{ (الإحماء) } \\
\hline د 9 & - تمارين إحماء،مرونة،تمطية & & \\
\hline ع د & - متمارين بد نية خاصة & & \\
\hline هد & - شرح الدهارة وعرض نموذج لها من الددرب & النشاط التعليمي & \\
\hline د & - يجلس اللاعب ثم يرقد على الأرض والذراعان بجانب & \multirow{17}{*}{ النشاط الذهني } & \\
\hline & الجسم،يغلق العينين ثم يبدأ بالتتفس مرتين & & \\
\hline & - ل - لبدء بعملية الاسترخاء & & \\
\hline ا & كيتصور اللاعب صورة الملعب الذي يتدرب علية & & \\
\hline ا & كيتصور اللاعب أن الملعب خال وانه موجود بمفرده & & \\
\hline ال ال & كيتصور اللاعب المهارة بشكل مجزأ & & \\
\hline & - تصور المهارة بشكل كامل & & \\
\hline د V & -تكرار التصور للمهارة (0)مراتهمع اخذ راحة .ب / ثا & & \\
\hline \multirow{9}{*}{ ثا. } & - - النهوض من وضع الاسترخاء & & \\
\hline & - تتفس عميق & & \\
\hline & - تحريك القدمين & & \\
\hline & - ثني ومد الذراعين مرتين & & \\
\hline & - تحريك الرأس قليلا & & \\
\hline & 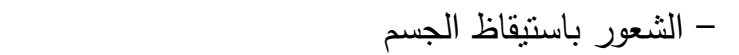 & & \\
\hline & - تنفس عميق مرة ثانية & & \\
\hline & - فتح العينين & & \\
\hline & - الثعور الكامل بالاستيقاظ ثم النهوض & & \\
\hline دOV & - ت - تمارين تطبيقية & النشاط النطبيقي & \\
\hline د & 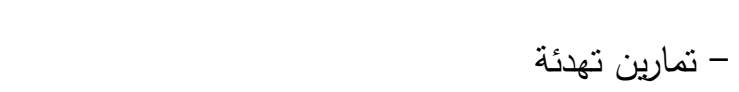 & 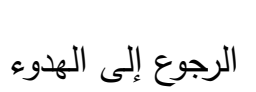 & لختامي \\
\hline$د$ د. & الزمن الكلي & & \\
\hline
\end{tabular}




\section{الملحق (ץ)}

يبين أقسام الوحدة التعليمية للمجموعة التجريبية الثانية

\begin{tabular}{|c|c|c|c|}
\hline الزمن & التمارين & النشاط & القسم \\
\hline د & _ تسجيل الحضور ، تهيئة الأدوات & المقدمة & \multirow{3}{*}{ (الإحماء) } \\
\hline 29 & _ تمارين إحماء، مرونة ، تمطية & الإحماء العام & \\
\hline$د \varepsilon$ & _ تمارين بدنية خاصة & الإحماء الخاص & \\
\hline rا & _مشاهدة أفلام وصور توضيحية للمهارة & النشاط التعليمي & \multirow{2}{*}{ الرئيسي } \\
\hline دOV & - تمارين تطبيقية & النشاط النطبيقي & \\
\hline د & - تمارين تهدئة & الرجوع إلى الهدوء & 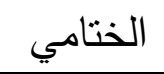 \\
\hline$د 9$. & الزمن الكلـــي & & \\
\hline
\end{tabular}

\section{الملحق (؛)}

يبين أقسام الوحدة التعليمية للمجموعة الضابطة

\begin{tabular}{|c|c|c|c|}
\hline 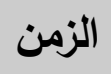 & التمارين & 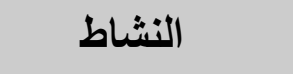 & 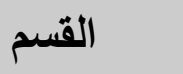 \\
\hline S & - تسجيل الحضور ، تهيئة الأدوات & المقدمة & التحضيري \\
\hline 9 & - تمارين إحماء ، مرونة ، تمطية & الإحماء العام & (الإحماء) \\
\hline ـ & - تمارين بدنية خاصة & الإحماء الخاص & \\
\hline سו & - شرح المهارة وعرض نموذج لها & النشاط التعليمي & الرئيسي \\
\hline$د O V$ & - تمارين تطبيقية & النشاط التطبيقي & \\
\hline د & - تمارين تهيئة & الرجوع إلى الهدوء & 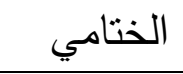 \\
\hline د & الزمن الكلـــي & & \\
\hline
\end{tabular}

